\title{
Biophysical isopycnic-coordinate modelling of plankton dynamics in the Arabian Sea
}

\author{
M.J. Olascoaga ${ }^{*}$, N. Idrisi, A. Romanou ${ }^{1}$ \\ RSMAS, University of Miami, 4600 Rickenbacker Cswy., Miami, FL 33149 USA
}

\begin{abstract}
A Nutrients-Phytoplankton-Zooplankton-Detritus (NPZD) ecosystem model is coupled to the Miami Isopycnic-Coordinate Ocean Model (MICOM) to study plankton dynamics in the Arabian Sea.

Experiments oriented to testing the NPZD-MICOM coupled model sensitivity to variations in several parameters are performed. Particular attention is paid to the rates of detritus sinking and maximum phytoplankton growth rate. The coarse features of the blooms are captured by all the experiments considered, and agree with earlier models for the biological activity of the region. Intensity, duration, and peaks of the blooms are found to be quite sensitive to the parameter choices. The existence of an offshore deep chlorophyll maximum in the model is found to be closely related to the increase of the detritus sinking rate. The use of temperaturedependent maximum growth rate of phytoplankton and the increase of detritus sinking rate are shown to improve model results compared with in situ and satellite observations.
\end{abstract}

The differences between the present results and those from previous modelling efforts in the region, where few- or multi-layer hydrodynamical models or even fixed-level hydrodynamical models have been employed, are found to be in the same range as the differences among the results from the various sensitivity experiments presented here. This indicates that a small uncertainty in the knowledge of the ecosystem model parameters can be more important in ecosystem modelling than the uncertainty associated to the differences in the vertical coordinate representation of the underlying hydrodynamical model.

There are still biological processes, such as denitrification which affect the vertical distribution of nutrient concentrations, that are not included neither in the previous works in the area nor in the present work. This might mask any potential advantages of the present MICOM-NPZD coupled model, especially at mid-depths in the ocean.

Key words: biophysical modelling, isopycnic model, Arabian Sea

\footnotetext{
* Corresponding author.

Email address: jolascoa@rsmas.miami.edu (M.J. Olascoaga).

1 Present affiliation: CIMS, New York University, New York, USA.
} 


\section{Introduction}

Under the monsoon atmospheric regime, the Arabian Sea shows strong seasonal variability. During the summer, southwesterly winds form the intense Findlater Jet over the western part of the basin (the Southwest Monsoon, hereafter SWM). Due to the favorable winds and vorticity balance, there is strong upwelling along the coasts of Somalia and Oman; the mixed layer shallows along the coast and deepens in the central Arabian Sea. During winter, significantly weaker winds are in the opposite direction (the Northeast Monsoon, hereafter NEM) and produce an increase in the mixed layer depth in the northern Arabian Sea. In response to the winds, the Somali Current changes direction semiannually, being strongest in the summer during the peak of the SWM when its transport resembles that of the Gulf Stream. The winter Somali Current flows southward and is much weaker than during the SWM. During low-wind intermonsoon periods, surface temperature rises and the mixed layer shallows.

The biophysical dynamics associated with the unique atmospheric forcing in the Arabian Sea are similar to the dynamics observed in temperate to high latitude regimes with distinct seasonal signals, unlike the nonseasonal dynamics observed in other tropical/subtropical regimes. During the SWM, upwelling brings nutrient-rich waters to the surface off the coasts of Somalia and Oman. Upwelling conditions, which start in May, lead to the initiation of diatom dominated phytoplankton blooms that persist until September (Gundersen et al., 1998; Latasa and Bidigare, 1998; Garrison et al., 2000). These phytoplankton blooms are apparent in field observations and satellite data during the SWM and spread well offshore of the initial upwelling regions. The phytoplankton blooms during the SWM are accompanied by large-bodied herbivorous copepods that dominate the zooplankton community; these include: Eucalanus crassus, Calanoides carinatus and Pleuromamma indica (Smith et al., 1998). In other seasons, the zooplankton community is dominated by smaller copepods, including Paracalanus spp., Acartia spp., and Oithona spp. (Smith et al., 1998). A less intense phytoplankton bloom develops in the northern Arabian Sea after the NEM. Cool, dry winds cause convective mixing and deepening of the upper mixed layer, entraining nutrient-rich waters into this layer leading to bloom conditions (Gardner et al., 1999; Wiggert et al., 2000). This bloom develops in February, lasts until March and is observed in field and satellite data.

Several coupled physical-biological models have been used to study biophysical interactions in the Arabian Sea. The physical models include layer primitive equations models (McCreary et al., 1996; Keen et al., 1997; McCreary et al., 2001; Hood et al., 2003), as well as fixed-level (z-coordinate) primitive equations models (Kawamiya, 2001; Kawamiya and Oschlies, 2003). Most of the above authors considered biological models with a small number of com- 
partments, typically nutrients, phytoplankton, zooplankton, and detritus. An exception is the work of Ryabchenko et al. (1998), who assumed a much simpler (quasigeostrophic) hydrodynamics but considered a more sophisticated (seven-compartment) biological model. All of the above works were able to reproduce - with varying degrees of accuracy - the most relevant features of the observed plankton dynamics associated with the unique atmospheric forcing in the Arabian Sea.

In this paper, the coupling of a Nutrients-Phytoplankton-Zooplankton-Detritus (NPZD) ecosystem model to the Miami Isopycnic-Coordinate Ocean Model (MICOM) is presented. This coupled model has served as a background for an individual-based model to study mechanisms for the emergence of copepods from diapause in the Somali Current (Idrisi et al., 2003). Yet the ecosystem dynamics results have been neither presented nor compared to those from the earlier modelling efforts, which either considered different vertical coordinate representations or more sophisticated biological models. Isopycnic-coordinate modelling has a number of advantages which are expected to contribute in the improvement of biological activity modelling. For instance, isopycniccoordinate models are known to minimize the production of spurious diapycnal mixing associated with truncation errors in the numerical representation of the advection of density in z-coordinate models (cf. e.g. Griffies et al., 2000). This property prevents the deep water masses from experiencing a spurious warming. Also, isopycnic-coordinate models diminish the vertical truncation errors by concentrating coordinate surfaces in regions with large vertical and horizontal buoyancy gradients. This property improves the representation of upwelling dynamics (Chassignet et al., 1996), which plays a key role in plankton dynamics of our study area. One of our goals is to test whether these properties amount to a better representation of the Arabian Sea ecosystem dynamics in comparison to the previous modelling efforts in the region. Also, a series of experiments are performed here to test the NPZD-MICOM coupled model sensitivity to variations in the parameters of the ecosystem model equations. This is aimed at making assessments of the relative importance of this sensitivity and that to the vertical coordinate representation of the physical model to which the biology is coupled.

In Section 2 the NPZD-MICOM coupled model is introduced. The most relevant features of the circulation in the Arabian Sea as simulated by MICOM are summarized in Section 3. The results of a series of experiments where the NPZD model parameters are varied are presented in Section 4; this is accompanied by a comparison with in situ and satellite data. The in situ data are obtained from the 1995 cruises of the Joint Global Ocean Flux Study (JGOFS) for several stations in the region and from the Netherlands Indian Ocean program. The satellite data used were obtained by the Sea-viewing Wide Field-of-view Sensor (SeaWiFS) Project chlorophyll $a$. In Section 5 the conclusions of the paper are presented. 


\section{NPZD-MICOM coupled model}

\subsection{Physical model}

The physical model used here is MICOM configured for the Arabian Sea (Esenkov, 2000). In MICOM each isopycnic layer is governed by the shallow water equations. The thermodynamic variables and the horizontal velocity are treated as "layer" variables that are vertically constant within layers but change discontinuously across layer interfaces. The first layer corresponds to an active mixed layer of the Krauss-Turner type, so it is a nonisopycnic layer and is subject to diabatic forcing. The wind and thermohaline forces expand and shrink the mixed layer, causing mass and other properties to exchange with the interior layers. The deepening of the mixed layer is caused by entrainment from the isopycnic layers due to strong enough winds, while the shoaling of the mixed layer is a result of heating in the absence of intense wind stirring. An important characteristic of MICOM for modelling upwelling regions is its ability to reduce the vertical truncation error by concentrating coordinates surfaces in regions with large vertical and horizontal density gradients. Also, the diapycnal component of numerically caused dispersion of material and thermodynamic properties is largely suppressed by formulating the equations in isopycnic coordinates. This characteristic allows MICOM to prevent the warming of deep water masses, as has been shown to occur in models framed in $z$-coordinates (Chassignet et al., 1996). Such spurious deep mixing is expected to affect also biological processes modelling. MICOM is well documented in the literature; for more details about it and its implementation see Bleck et al. (1992) and references therein.

The model domain occupies a region between $4^{\circ} \mathrm{S}$ and $23^{\circ} \mathrm{N}$, and $40^{\circ} \mathrm{E}$ and $68^{\circ} \mathrm{E}$ with $0.35^{\circ}$ resolution in the horizontal (Fig. 1). It has 15 isopycnic layers below the mixed layer. The vertical structure of the upper thermocline is reasonably well resolved with seven layers in the upper $400 \mathrm{~m}$. With the use of this relatively high spatial resolution the intense eddy activity that dominates the system (Flagg and Kim, 1998; Kim et al., 2001) is quite well reproduced (Esenkov, 2000). The global solution of MICOM after 50 years of integration from an initialization with Levitus data (Levitus and Boyer, 1994) is used for the initial and open boundary conditions of the regional model. Formulation of open boundary conditions is based on Bleck and Sun (1996) and presented in Esenkov and Olson (2002). Interface pressure nudging, damping of the tendency term in the continuity equation, and enhanced viscosity in the momentum equations are applied in a finite-width "sponge" zone near the open boundaries. The width of the sponge zone was determined experimentally and amounted to 7 grid points (Esenkov, 2000). The open-boundary model was validated first through a detailed comparison of the results with the output of the global model (Esenkov, 2000). Finally, the model is forced by monthly mean fields of atmospheric temperature, humidity, and wind stress from COADS; net radiation from the Oberhüber Atlas; and precipitation from 


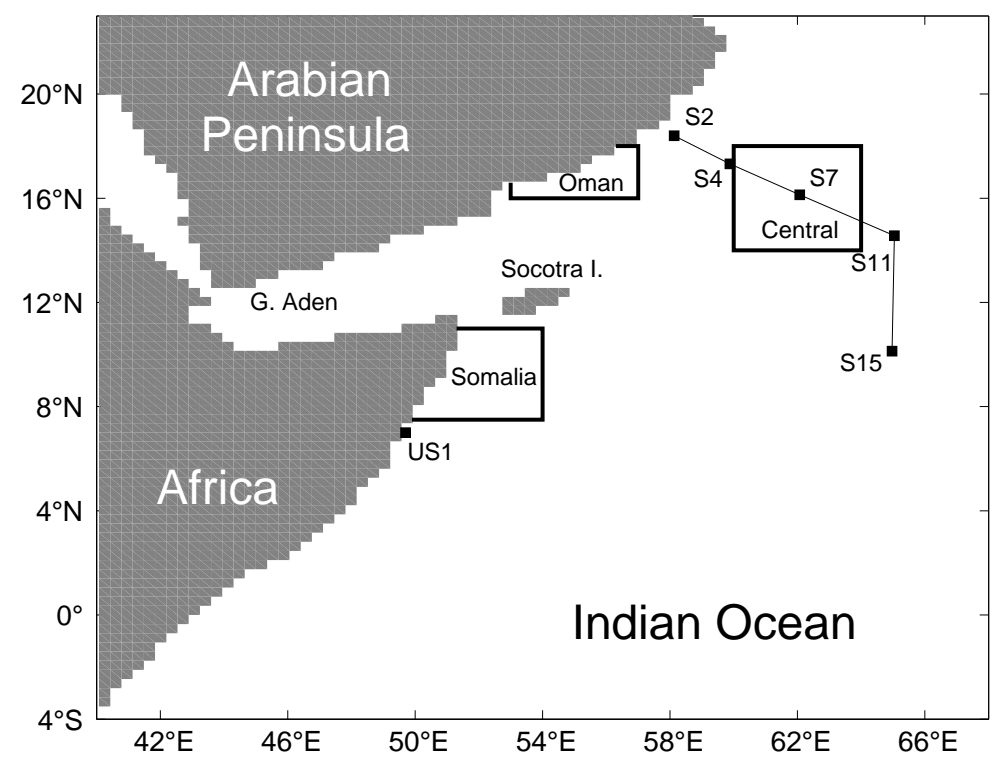

Fig. 1. Map of the model study area. The U.S. Joint Global Ocean Flux Study (U.S. JGOFS) stations (S2, S4, S7, S11 and S15), as well as the Netherlands Indian Ocean program station US1 are shown as squares. Marked sections for Oman, Somalia and Central were used to present model results.

the NOAA microwave sounding unit.

\subsection{Biophysical coupling}

The NPZD biological model determines the nitrogen concentration in four compartments: nutrients $(N)$, phytoplankton $(P)$, zooplankton $(Z)$, and detritus $(D)$. The concentration of compartment $\varphi$ is controlled by a local conservation equation of the form

$$
\partial_{t}(h \varphi)+\nabla_{s} \cdot\left[h\left(\mathbf{u}-\kappa \boldsymbol{\nabla}_{s}\right) \varphi\right]+F_{+}-F_{-}=h \mathcal{S}_{\varphi}
$$

In this equation, $\nabla_{s}$ acts along a surface with generalized coordinate $s$, which makes the equation valid for the surface mixed layer and the isopycnic layers; $h$ is the layer thickness; $\mathbf{u}$ is the horizontal velocity within the layer; $\kappa$ is a variable eddy viscosity coefficient; $F_{ \pm}$represents the vertical flux across the top $(+)$ and bottom $(-)$ interfaces of the layer; and $\mathcal{S}_{\varphi}$ denotes the biological source-sink term.

Four different processes control the vertical exchange of biological properties among the layers. These processes are diapycnal mixing, deep convection, cabbeling, and mixed-layer entrainment/detrainment. The four processes are well documented in the MICOM User Manual at the WWW address http://www.acl.lanl.gov/CHAMMP/micom.html.

The NPZD system source-sink coupling terms, which represent the predatorprey dynamics in each layer, are given by 


$$
\begin{aligned}
& \mathcal{S}_{P}=G P-\Phi_{P} Z-\sigma_{P} P \\
& \mathcal{S}_{Z}=A_{e} A_{m}\left(\Phi_{P}+\Phi_{D}+\Phi_{Z}\right) Z-\Phi_{Z} Z \\
& \mathcal{S}_{D}=\left(\Phi_{P}+\Phi_{Z}\right)\left(1-A_{e}\right) Z A_{e} \Phi_{D} Z+\sigma_{P} P-\rho_{D} D-w_{\mathrm{s}}\left(D-D_{>}\right) \\
& \mathcal{S}_{N}=\left(1-A_{m}\right) A_{e}\left(\Phi_{P}+\Phi_{D}+\Phi_{Z}\right) Z+\rho_{D} D G P
\end{aligned}
$$

for the phytoplankton, zooplankton, detritus and nutrients source-sink terms respectively. Following is a brief explanation of the terms in (2) (for a complete description see Lima et al., 2002).

Phytoplankton growth is expressed as

$$
G=P_{\max } \mathcal{F}(T) \bar{I} \frac{N}{N+N_{0}}
$$

where

$$
\mathcal{F}(T)=\frac{1}{2}\left[a(T)^{b} \mathrm{e}^{b[1-a(T)]}+1\right], \quad a(T)=\frac{T_{\max }-T}{T_{\max }-T_{\mathrm{opt}}},
$$

and

$$
\bar{I}=\frac{1}{z^{-}-z^{+}} \int_{z^{-}}^{z^{+}} \frac{I}{\sqrt{I^{2}+I_{0}^{2}}} \mathrm{~d} z,
$$

which is the average light intensity within each layer (McCreary et al., 1996). In (4), $I=I_{\text {surf }} \mathrm{e}^{k z^{+}} \mathrm{e}^{k\left(z-z^{+}\right)}$, where $k=k_{w}+k_{p} P$, and $I_{0}$ is the light saturation constant. The surface light intensity, $I_{\text {surf }}$, is taken from the Oberhüber Atlas. For growth due to the nutrient supply, we use the Michaelis-Menten form $N /\left(N+N_{0}\right)$, where $N_{0}$ is the half-saturation constant. We have allowed the phytoplankton maximum growth rate to vary with temperature, $T$, according to $P_{\text {max }} \mathcal{F}(T)$. This function is based on the premise that the biological process has a maximum reaction rate at some optimum temperature, $T_{\mathrm{opt}}$, and diminishes asymmetrically as environmental temperature moves away from the optimum (Thornton and Lessem, 1978; Eppley, 1972). The effect of a constant vs. temperature-dependent phytoplankton growth rate is evaluated and discussed later in this paper. Phytoplankton losses in (2) are through zooplankton grazing $\Phi_{P}$ and senescence $\sigma_{P}$. The zooplankton grazing rate in (2) contains total feeding preference based on each $\varphi=(N, P, Z, D)$ (Lima et al., 2002)

$$
\Phi_{\varphi}=\frac{\gamma_{\max } \phi_{\varphi} \varphi^{2}}{\left(\phi_{P} P+\phi_{D} D+\phi_{Z} Z\right) K_{Z}+\phi_{P}^{2} P^{2}+\phi_{D}^{2} D^{2}+\phi_{Z}^{2} Z^{2}},
$$

where $\phi_{\varphi}$ is the individual feeding preference for each compartment. The zooplankton concentration in (2) losses are due to self-predation $\Phi_{Z}$. The sources for detritus in (2) are the senescence of phytoplankton $\sigma_{P}$, zooplankton mortality, and fecal pellets produced by zooplankton grazing. The losses in this compartment occur through remineralization $\rho_{D}$ and zooplankton predation $A_{e} \Phi_{D}$. Detritus in (2) is allowed to sink in the model according to $h w_{\mathrm{s}}\left(D-D_{>}\right)$(Keen et al., 1997), where $w_{\mathrm{s}}$ is the (constant) sinking rate of 
detritus and $D_{>}$denotes the detritus concentration in the layer just above the layer in question. The concentration of nutrients in (2) is regenerated from zooplankton excretion and the remineralization of detritus. Nutrient loss is through phytoplankton uptake. The parameter choices for the coupled NPZD equations are given in Table 1. Most of the parameter values are taken from Lima et al. (2002); in particular, the detritus sinking rate value is chosen as in Keen et al. (1997). These values are within the range of observations in the region (Caron and Dennett, 1999; Roman et al., 2000); similar choices have been used by other authors (McCreary et al., 1996; Kawamiya, 2001). One of the problems in ecosystem modelling is to choose an adequate set of parameters; sensitivity experiments that treat the problem of parameter choice will be discussed in Section 4.2.

The NPZD model components are set to linearly follow the tendency within the sponge zone at the open boundaries. The initial conditions for the NPZD model variables are derived from the U.S. Joint Global Ocean Flux Study (JGOFS) dataset. For the initial concentrations of $P, Z$, and $D$, averaged values for each layer were used, whereas for $N$ a regression of nitrate on temperature was employed. The NPZD-MICOM coupled model is initially integrated for 4 years. After the fourth year of integration the NPZD model variables reach an equilibrium in all the area of study, except for the nutrients in the northern Arabian Sea. In that region, in the upper mixed-layer and intermediate layers they increase at a rate that depends on the choice of the sinking rate of detritus. This will be discussed in more detail in Section 4.2. The experiments presented in the following section correspond to the fifth year of integration.

\section{Physics}

In this section the most relevant aspects of the circulation in the Arabian Sea region as simulated by MICOM are summarized (for an extensive discussion see Esenkov, 2000; Esenkov and Olson, 2002; Esenkov et al., 2003).

Mixed layer depth and circulation for January 1, April 1, July 1, and October 1 of the fifth year of model run are shown in Fig. 2. The NEM is at its peak in January (Fig. 2, upper-left panel). The northeasterly winds carry cool, dry, continental air into the region, resulting in a large heat loss through the ocean surface. This cooling produces a strong entrainment of fluid from the deep layers into the mixed layer, which deepens throughout the northern Arabian Sea. The North Equatorial Current flows westward between the equator and about $5^{\circ} \mathrm{N}$ with speeds up to $60 \mathrm{cms}^{-1}$. The Somali Current flows southwestward during this season. The winds weaken in the spring and in response the mixed layer shallows (Fig. 2, upper-right panel). The Somali

Current flows northward and the North Equatorial Current flows eastward forced by the westerlies. As the southwesterly winds strengthen the Southern 


\begin{tabular}{lcc}
\hline \hline \multicolumn{1}{c}{ Parameter } & Symbol & Value \\
Phytoplankton Maximum Growth Rate & $P_{\max }$ & $1.5 \mathrm{~d}^{-1}$ \\
Saturation Constant for Light & $I_{0}$ & $40 \mathrm{Wm}^{-2}$ \\
Clear Water Atten. Coeff. & $k_{w}$ & $0.03 \mathrm{~m}^{-1}$ \\
Attenuation Coeff. due to Phytoplankton & $k_{p}$ & $0.038\left(\mathrm{mmol} \mathrm{N}^{-1} \mathrm{~m}^{2}\right.$ \\
Half-Saturation Constant for $N$ Uptake & $N_{0}$ & $1 \mathrm{mmol} \mathrm{N} \mathrm{m}^{-3}$ \\
Half-Saturation Constat for $Z$ Grazing & $K_{Z}$ & $1 \mathrm{mmol} \mathrm{N} \mathrm{m}^{-3}$ \\
Zooplankton Grazing & $\gamma_{\max }$ & $0.75 \mathrm{~d}^{-1}$ \\
Zooplankton Feeding Preference for $P$ & $\phi_{P}$ & 0.5 \\
Zooplankton Feeding Preference for $Z$ & $\phi_{Z}$ & 0.3 \\
Zooplankton Feeding Preference for $D$ & $\phi_{D}$ & 0.2 \\
Senescence of Phytoplankton & $\sigma_{p}$ & $0.01 \mathrm{~d}^{-1}$ \\
Zooplankton Assimilation Efficiency & $A_{e}$ & 0.8 \\
Zooplankton Metabolic Efficiency & $A_{m}$ & 0.25 \\
Detrital Remineralization Rate & $\rho_{D}$ & $0.05 \mathrm{~d}^{-1}$ \\
Detrital Sinking & $w_{\mathrm{s}}$ & $0.2 \mathrm{~d}^{-1}$ \\
Optimal Temperature & $T_{\mathrm{opt}}$ & $25{ }^{\circ} \mathrm{C}$ \\
Maximum Tolered Temperature & $T_{\max }$ & $27{ }^{\circ} \mathrm{C}$ \\
Coefficient in Formula (3) & $b$ & 0.117 \\
\hline
\end{tabular}

Table 1

Parameter choices for the biophysical coupling. The values refer to the NPZD model equations (2) and were chosen to agree with previous similar studies.

Gyre starts forming south of $4^{\circ} \mathrm{N}$ and upwelling takes place along the Somali and Omani coasts. Intensified SW (summer) Monsoon winds lead to a strengthening of the Southern Gyre and the appearance of another eddy, the Great Whirl, between $5^{\circ} \mathrm{N}$ and $10^{\circ} \mathrm{N}$, in early June. The Southern Gyre circulation is not closed and feeds an eastward current along the equator. Both eddies intensify in July, during the peak of the SWM, and a third gyre forms farther east with a center near $5^{\circ} \mathrm{N}$ (Fig. 2, bottom-left panel). The gyres are very strong, with current speeds exceeding $2 \mathrm{~m} \mathrm{~s}^{-1}$ on their western and northern sides. A much weaker pair of anticyclonic eddies is present off the Arabian coast during the SWM. In September, the winds weaken to about half their peak value. As a consequence, the mixed layer shallows over most of the Arabian Sea. The coastal current is still northward but is disconnected near $4^{\circ} \mathrm{N}$ in October (Fig. 2, bottom-right panel). The southern part turns offshore south of $4^{\circ} \mathrm{N}$ producing a recirculation pattern like that associated 

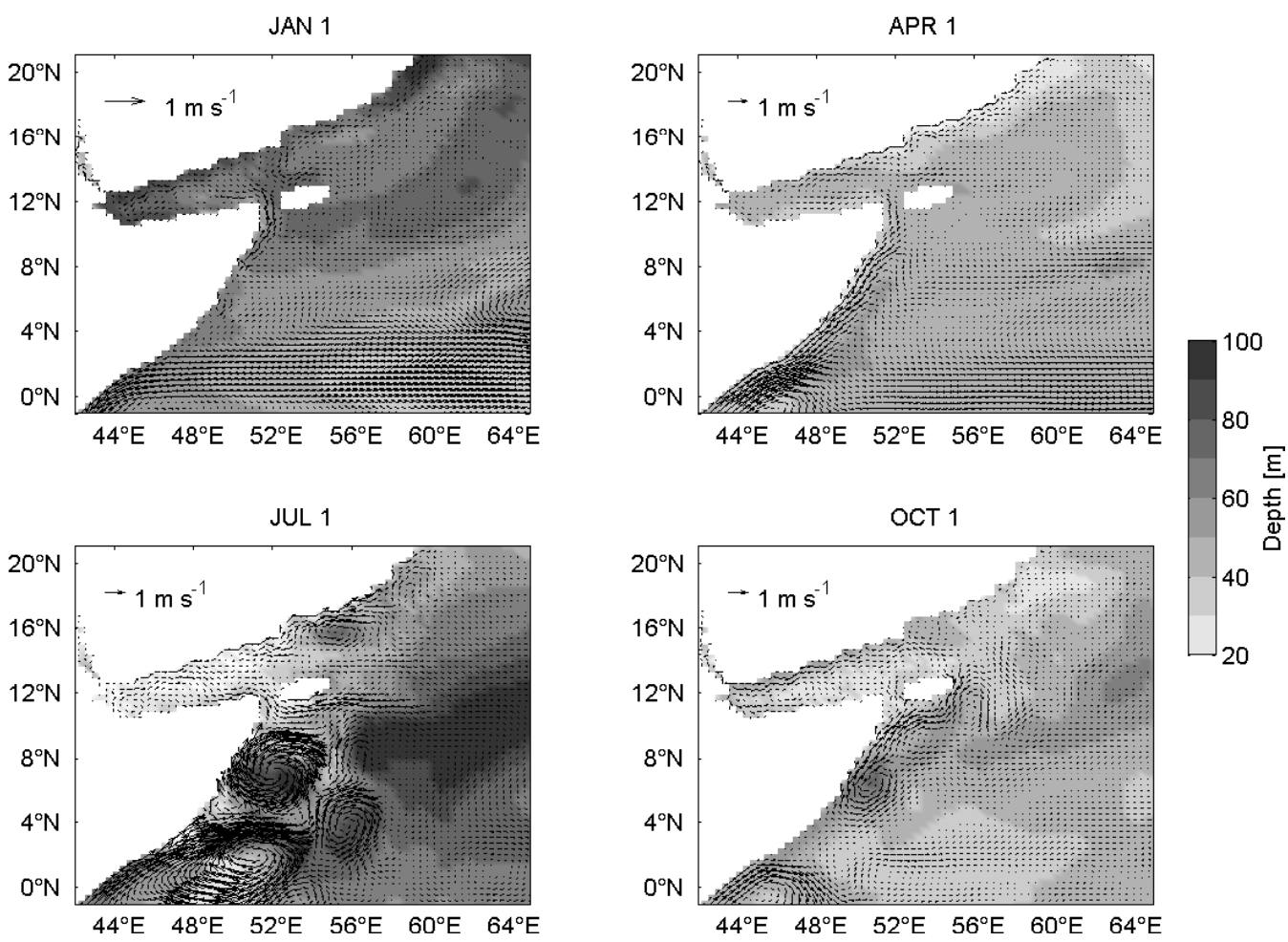

Fig. 2. Mixed layer depth (color map) and velocity fields (arrows) at four different instances during the fifth year of the biophysical model run.

with the Southern Gyre in the early summer. The winter circulation regime, with the formation of the southward Somali Current reappears in December. This current intensifies throughout the NEM and peaks in January.

Rigorous comparison of the physical model results to the observations is given by (Esenkov, 2000; Esenkov and Olson, 2002; Esenkov et al., 2003) and shows that the physical fields simulated with MICOM are very realistic. This is important because the phytoplankton growth is very sensitive to light intensity and therefore a correct representation of mixed layer dynamics is crucial to model biophysical interactions. This is largely attained by MICOM, which correctly reproduces the observed seasonal variation of the mixed layer depth. Upwelling and downwelling are other physical features which are of great importance for biological processes. The rates predicted by MICOM largely match the observations.

\section{Biophysics}

Several numerical experiments are performed here using different biological parameter choices (cf. Table 2). Experiment E1 is the base experiment. In some of the experiments a temperature-dependent function for the maximum growth rate of phytoplankton is employed (experiments E1, E2, E5 and E6). 


\begin{tabular}{ccccccc}
\hline \hline Experiment & $\gamma_{\max }\left[\mathrm{d}^{-1}\right]$ & $P_{\max }\left[\mathrm{d}^{-1}\right]$ & $\mathcal{F}(T)$ & $T_{\max }\left[{ }^{\circ} \mathrm{C}\right]$ & $T_{\mathrm{opt}}\left[{ }^{\circ} \mathrm{C}\right]$ & $w_{s}\left[\mathrm{~d}^{-1}\right]$ \\
E1 & 0.75 & 1.5 & Yes & 28 & 25 & 0.2 \\
E2 & 0.75 & 1.5 & Yes & 27 & 22 & 0.2 \\
E3 & 0.75 & 0.7 & No & - & - & 0.2 \\
E4 & 1 & 2 & No & - & - & 0.2 \\
E5 & 0.75 & 1.5 & Yes & 28 & 25 & 0.05 \\
E6 & 0.75 & 1.5 & Yes & 28 & 25 & 0 \\
\hline
\end{tabular}

Table 2

Parameter choices for the sensitivity experiments performed in this work. Explanation of the parameters is given in Table 1 .

In E3 and E4 the phytoplankton maximum growth rate is assumed to be temperature independent. Also different sinking rates are tested; experiments E5 and E6 assume much reduced detrital sinking rates than the base experiment E1. In general, the parameter selection is made following previous work in the area or using averaged values from the U.S. JGOFS dataset. In particular, the temperature dependence of the phytoplankton growth rate aims to simulate the differences observed during the monsoon and intermonsoon seasons (Caron and Dennett, 1999). As there is not enough data to evaluate the maximum phytoplankton growth rate, the choice of parameters in formula (3) has been quite arbitrary. Two different temperature configurations have been tested in particular. The choice of all the temperature parameters in E1 is made following the observed surface temperature during the NEM, SWM, and the intermonsoon seasons. In experiment E2 the optimum and maximum temperature values are reduced to test the influence on the dynamics of the blooms. The parameters in the experiment E4 are chosen as in Lima et al. (2002). Observations indicate that the zooplankton grazing does not have a significant seasonal signature (Caron and Dennett, 1999; Roman et al., 2000); consequently, we have considered a constant value in all of our experiments. In the rest of this section the results from the most significant numerical experiments are presented and discussed.

\subsection{General features of the NPZD dynamics}

\subsubsection{Mixed layer biophysics}

From late April to August, the SWM upwelling-favorable winds blow along the coasts of Somalia, south of Socotra Island, and the Arabian Peninsula. In response to this forcing, the model, in all the experiments considered, predicts nutrient-rich waters flowing into the mixed layer in these regions (Fig. 3). Consequently, elevated concentrations of phytoplankton in these same regions are also predicted by all the experiments. Off Oman, the region with high nutrient and phytoplankton concentrations extends over a large area offshore. The region of high concentrations off Somalia reflects the shape of the Great Whirl and the northern edge of the South Gyre. Even though these features 

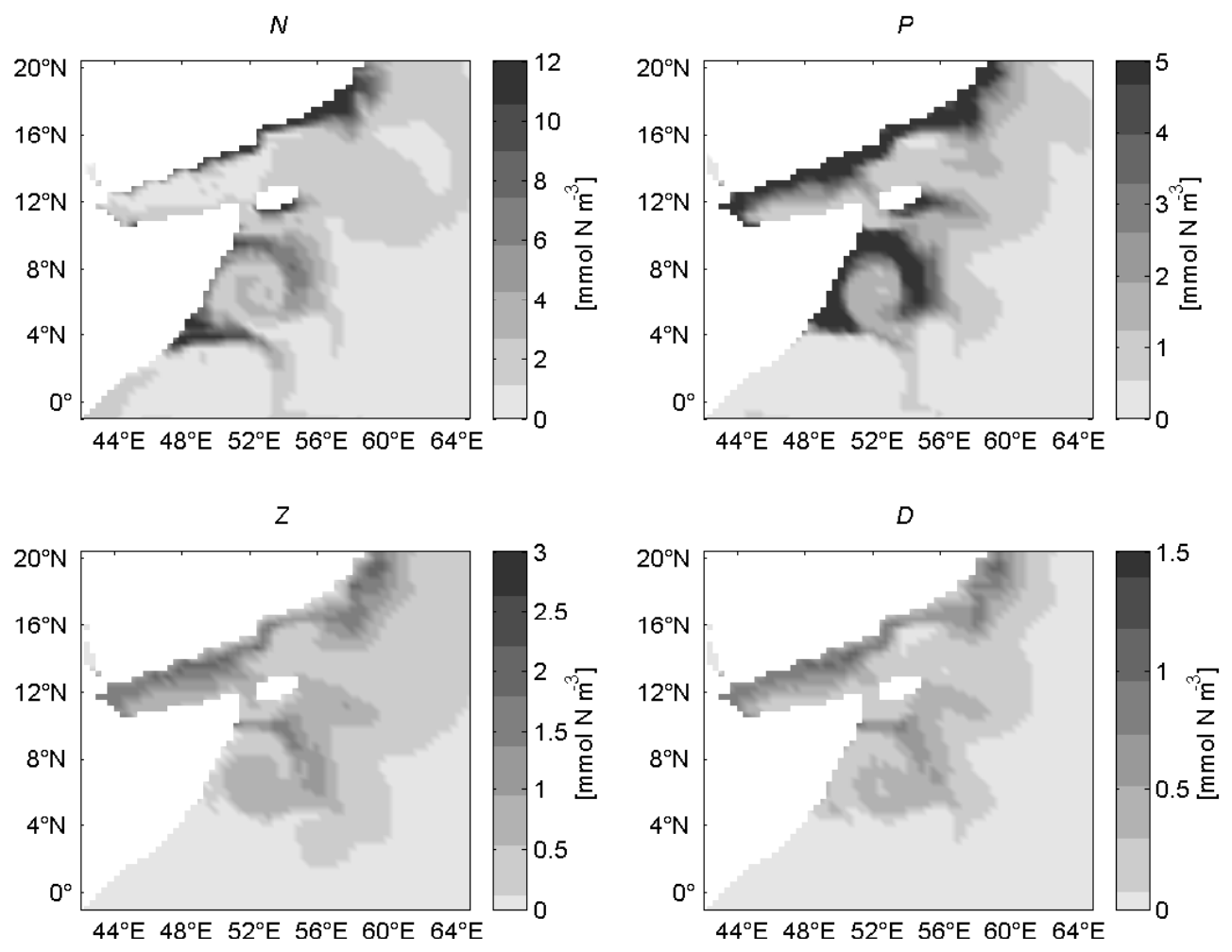

Fig. 3. NPZD model variables in the mixed layer averaged over June for experiment E1.

are common to all experiments considered in this paper, the intensity of the blooms and the offshore extensions vary somewhat. Notable fact in Fig. 3 is also that the zooplankton and detritus concentrations are maximum farther offshore than the phytoplankton and nutrient concentrations off the coast of Oman. This characteristic result is common to all the experiments. This aspect of the zooplankton dynamics has been particularly remarked by Spitz et al. (2003).

During the NEM, cool and dry winds cause convective mixing and deepening of the mixed layer (Fig. 2 upper-left panel). In response, nutrient-rich waters entrain into this layer leading to bloom conditions. Experiments E1 (Fig. 4) and E4 predict a phytoplankton bloom in the northern Arabian Sea with moderate concentrations extending offshore. Accompanying the phytoplankton bloom, a high concentration of zooplankton and detritus is predicted by experiments E1 and E4. Experiments E2 and E3 also predict a phytoplankton bloom after the NEM in the northern Arabian Sea. However, in both experiments the bloom lasts longer and is less intense. Even though experiments E2 and E3 show an increase of nutrients in the mixed layer, the zooplankton grazing and phytoplankton growth almost balance one another. 

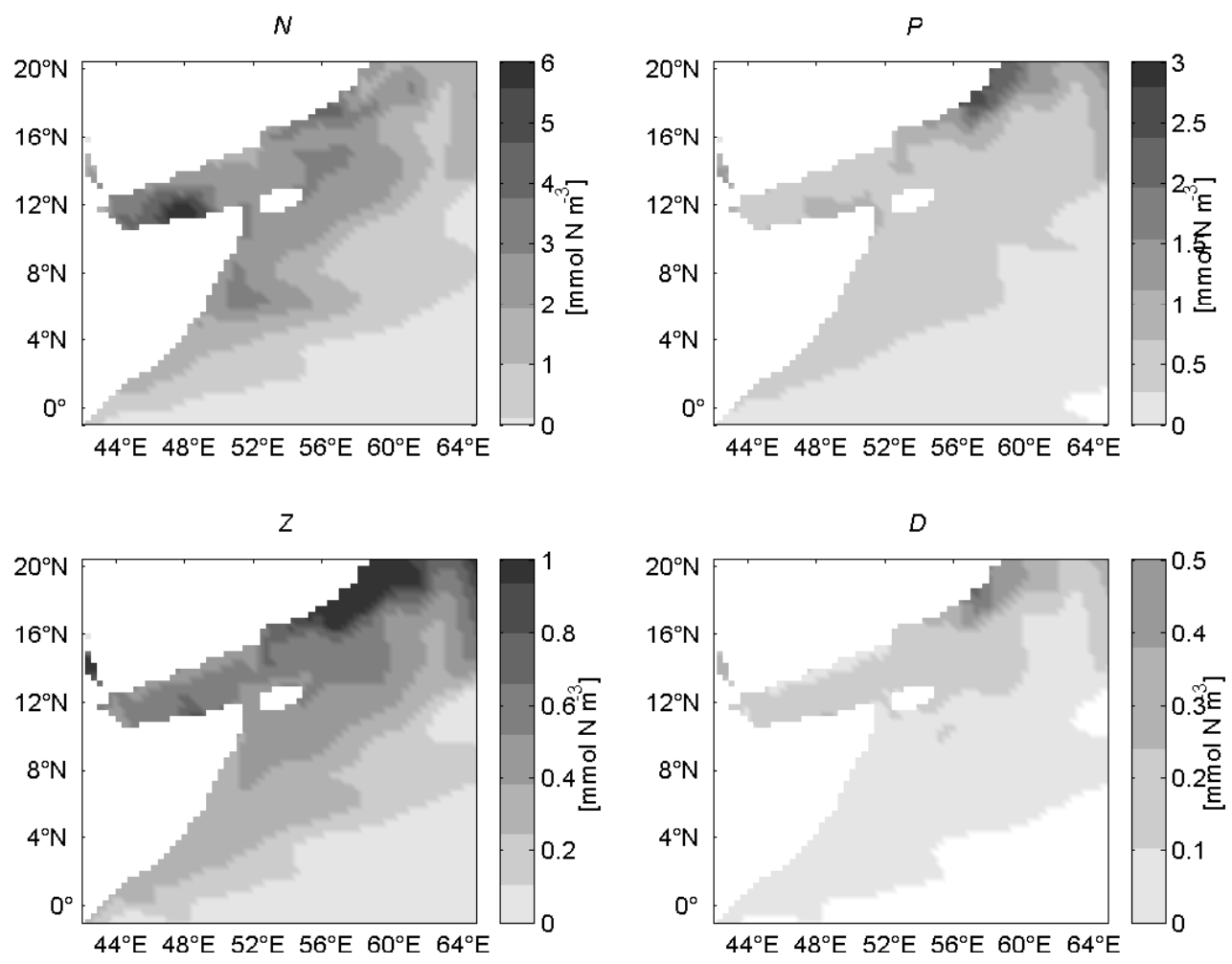

Fig. 4. NPZD model variables in the mixed layer averaged over February for experiment E1.

\subsubsection{Phytoplankton vertical structure}

Fig. 5 shows the annual cycle for phytoplankton concentration at locations S2, S15 and US1 from experiment E1. These three locations were chosen in order to exemplify the Omani (S2) and Somali (US1) coastal and the offshore (S15) biophysical dynamics.

At position S2 the model produces two blooms, the first one in February with moderate concentration level and duration, and the second bloom begins in late May and extends to October with a significant peak in August (Fig. 5, upper panel). These two blooms are associated with two different processes. The first one is due to the shoaling of the mixed layer, while the second relates to the increase of nutrients in the upper layer due to upwelling. During the winter, elevated concentrations of nutrients in the upper mixed layer are entrained due to the mixing produced by the wind stress. This leads to relatively high values of phytoplankton in February, precisely when there is also a decrease in the thickness of the mixed layer. Notice that, in November, when the entrainment of nutrients starts, there is an increase of phytoplankton concentration. However, at that time as the mixed layer thickness increases the light becomes the limiting factor for the maintenance of the bloom. At the be- 


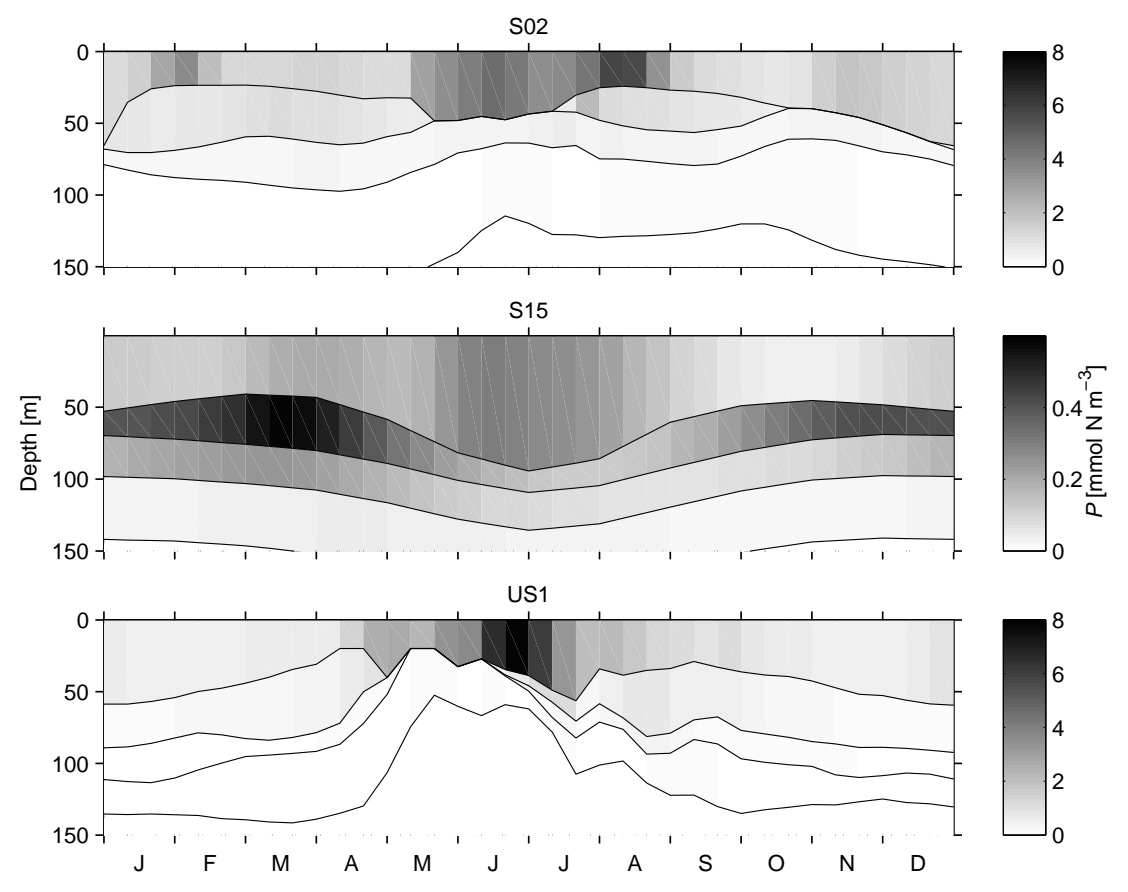

Fig. 5. Annual cycle of the phytoplankton concentration at locations S2, S15, and US1 (cf. Fig. 1) for experiment E1. Horizontal lines denote layer interfaces. Note that the coloraxis limits for the middle panel are much less than for the other two sections.

ginning of the SWM (May), an increase in nutrient concentrations is present in the model simulation. This increase is due to upwelled waters (not deeper than $100 \mathrm{~m}$ ), rich in nutrients coming in contact with the mixed layer. Along with this increase in nutrients, the phytoplankton has two distinct peaks, one at the beginning of June and the second and more intense bloom in August.

At position S15, which is farther offshore and to the south of S2 (Fig. 1), the model produces moderately high phytoplankton concentrations from June to September (Fig. 5, middle panel). It is remarkable that the model is able to sustain a deep chlorophyll maximum $(D C M)$ from late August to late May. This extended period of the deep chlorophyll maximum is not present in the simulations with no temperature-dependent maximum growth rate of phytoplankton (experiments E3 and E4) and it disappears completely in experiments with no temperature-dependent maximum growth rate of phytoplankton and detritus sinking (experiment not shown). Thus the development of a DCM largely depends on the detritus sinking intensity. A comparison with in situ data at these two locations (S2 and S15) will be done in Section 4.3.1.

The bottom panel of Fig. 5 shows the Somali bloom at the US1 location (cf. Fig. 1) during the SWM, which is a clear example of an upwelling bloom. In this case, the source of nutrients is located deeper than $100 \mathrm{~m}$ (the upwelled water can originate from around $300 \mathrm{~m}$ at the Somali coast). Although the 
bloom at this location is more intense than the one observed at S2 off Oman, it does not last as long. The relatively high intensity of this bloom is associated with the fact that the source of nutrient is in deeper water masses. The short duration of the bloom, in turn, is a consequence of the short residence time of water near the surface in the Somali region (van Couwelaar, 1997). Patches of high chlorophyll $a$ content with a mean of about $3 \mathrm{mg} \operatorname{chl} a \mathrm{~m}^{-3}$ and concentrations as high as $15 \mathrm{mg}$ chl $a \mathrm{~m}^{-3}$ were observed in this region for the SWM season during the Netherlands Indian Ocean Program in 1992-1993 (Veldhuis et al., 1997; Baars et al., 1994). During the NEM, the observed chlorophyll $a$ concentrations are less than $0.20 \mathrm{mg}$ chl $a \mathrm{~m}^{-3}$ (Krey, 1973).

The characteristics of the blooms (i.e. intensity, duration and peaks) are much more sensitive to the choice of parameters. The differences among experiments will be discussed in the next section.

\subsection{Sensitivity to variations in the NPZD model parameters}

In the next section, a short presentation and discussion is given about those experiments which are considered most relevant in understanding how a poor knowledge of the ecosystem model parameters can have a substantial impact on the ecosystem modelling results. To facilitate the comparison with previous works, the results are averaged within each of the three regions indicated in Fig. 1. Thus the figures presented in the following can be compared to Fig. 18 of Kawamiya and Oschlies (2003), Fig. 4 of McCreary et al. (1996), and Fig. 1 of Ryabchenko et al. (1998).

\subsubsection{Phytoplankton maximum growth rate}

In the baseline model run (experiment E1) the parameter values used are the most realistic compared to data and previous works, with $P_{\max }$ including a temperature-dependence function (Table 1 and Table 2). The trend in nutrients predicted by experiment E1 shows a distinct increase in the early SWM that coincides with the onset of upwelling along the coasts of Somalia and Oman (Fig. 6 upper two panels) and which causes the peak of phytoplankton concentration noted in Fig. 5 bottom panel. Peak concentrations are higher off Oman (12-13 mmol $\left.\mathrm{N} \mathrm{m}^{-3}\right)$, which lag by about 20 days the peak concentrations off Somalia $\left(\sim 6 \mathrm{mmol} \mathrm{N} \mathrm{m}{ }^{-3}\right)$. The lowest nutrient concentrations in both regions occur during the spring intermonsoon season. Simulation E1 does not suggest any distinct seasonal trend apparent within the central Arabian Sea basin (Fig. 6 bottom panel).

Experiment E1 predicts a small bloom during the NEM off Somalia and Oman (Fig. 7 upper two panels, solid light line). Omani waters have higher phytoplankton concentration than Somali waters $\left(\sim 2\right.$ vs. $1.2 \mathrm{mmol} \mathrm{N} \mathrm{m}{ }^{-3}$ on average) and also the bloom occurs earlier. Prominent peaks in phytoplankton concentrations are predicted by experiment E1 off Oman and Somalia during 

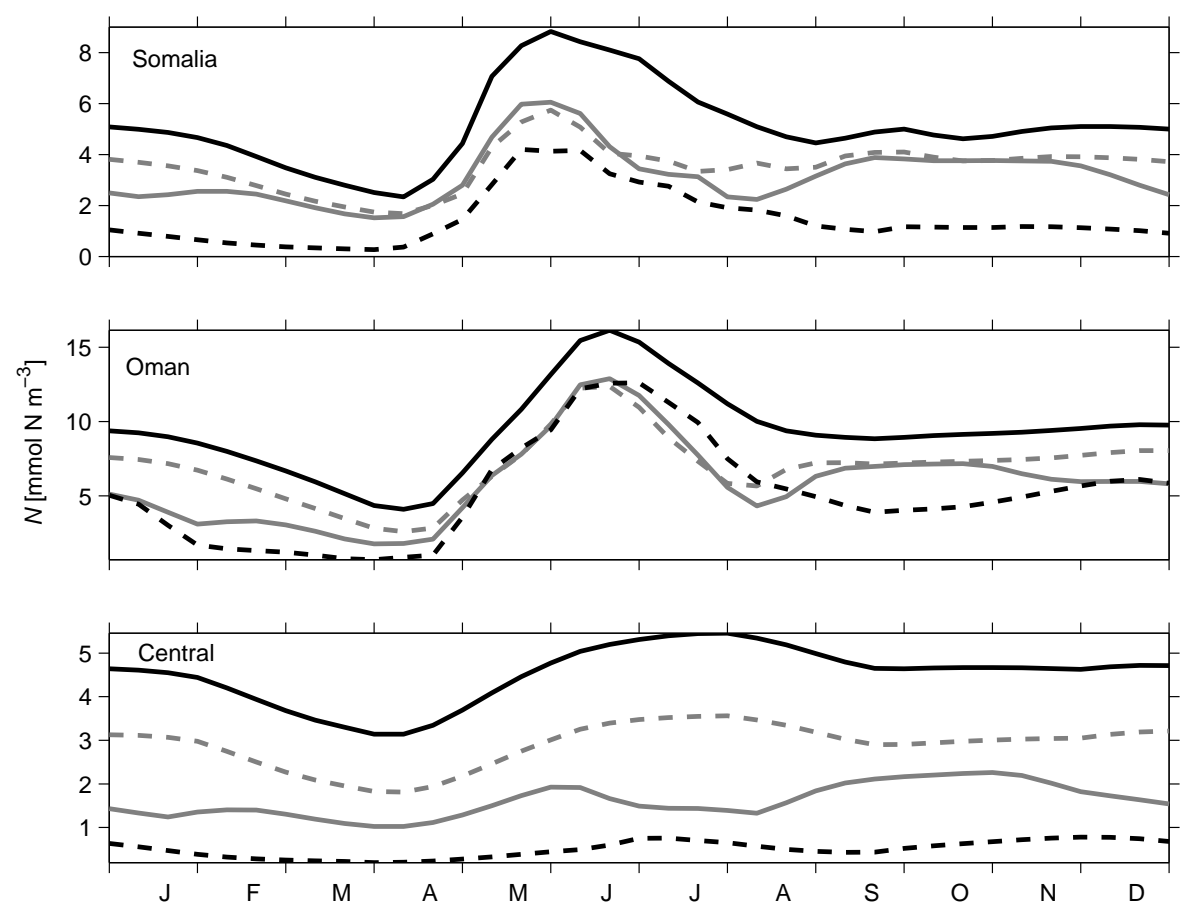

Fig. 6. Annual cycle of the nutrient concentration in the mixed layer in three regions indicated in Fig. 1 as predicted by experiments E1 (solid light), E2 (dashed light), E3 (solid dark) and E4 (dashed dark). Description of the different experiments is given in Table 2. Note scale changes among panels.

the SWM, with the Omani waters having higher concentrations $(6.3 \mathrm{mmol} \mathrm{N}$ $\mathrm{m}^{-3}$ ) compared to Somali waters $\left(4.3 \mathrm{mmol} \mathrm{N} \mathrm{m}^{-3}\right)$. Both peaks lagged the upwelling of nutrients by about a month. Phytoplankton concentrations in the central Arabian Sea basin never exceed $1.2 \mathrm{mmol} \mathrm{N} \mathrm{m}^{-3}$ (maximum concentration during the SWM), with minimum concentration dropping to $0.4 \mathrm{mmol}$ $\mathrm{N} \mathrm{m}^{-3}$ (early $\mathrm{NEM}$ ). The likely cause for the SWM peak in the central basin is due to advection offshore of upwelled waters originating near the Omani coast (Keen et al., 1997; Kawamiya, 2001).

Both the zooplankton and detritus concentrations show trends similar to phytoplankton concentration in simulation E1 for Omani and Somali waters, with a lag of about one month (Figs. 8 and 9 solid light line). As with the phytoplankton and nutrient concentrations, the SWM peaks are greater off Oman compared to Somali waters. The peaks in zooplankton and detritus off Oman are much sharper than the peak in phytoplankton in the same region during the SWM. There is a small but distinct peak in the concentrations of zooplankton and detritus during the NEM. In the central Arabian Sea basin, the zooplankton and detritus concentrations have small peaks during the NEM followed by a higher peak during the SWM.

In experiment E2, which differs from E1 in that the maximum tolerated temperature $T_{\max }$ and $T_{\mathrm{opt}}$ are slightly reduced, nutrient concentrations are ele- 

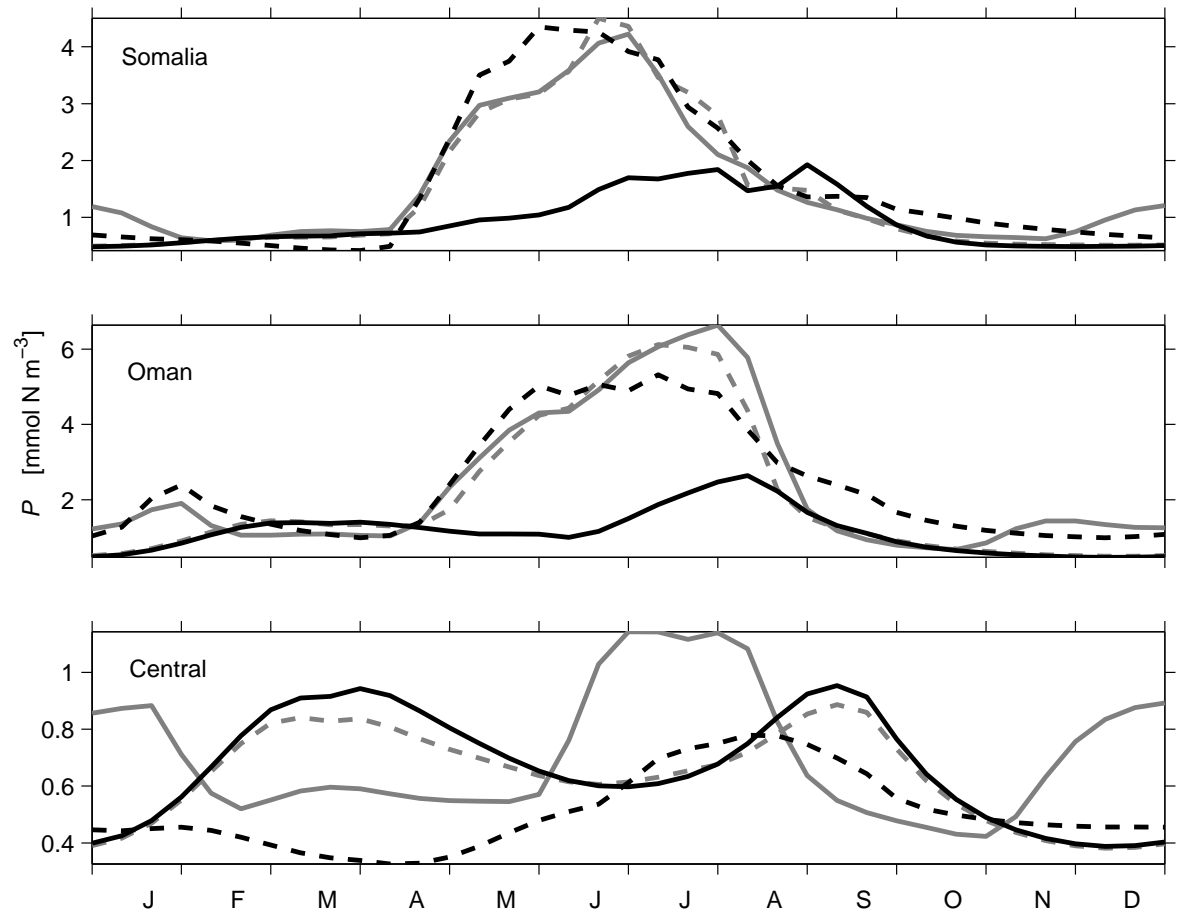

Fig. 7. Annual cycle of the phytoplankton concentration in the mixed layer in three regions indicated in Fig. 1 as predicted by experiments E1 (solid light), E2 (dashed light), E3 (solid dark) and E4 (dashed dark). Description of the different experiments is given in Table 2. Note scale changes among panels.

vated in comparison to experiment E1 during the NEM in both Somali and Omani waters (Fig. 6). In the central basin, nutrient concentrations in experiment E2 are higher than in E1 all year round. Phytoplankton concentrations in E2 exhibit no blooms during NEM off Somalia and Oman (Fig. 7). In the Central basin, phytoplankton concentrations range between 0.4 and $0.8 \mathrm{mmol}$ $\mathrm{N} \mathrm{m}^{-3}$ with two peaks during both the spring and fall intermonsoon periods. Experiment E1 and E2 agree very well at the Somalia and Oman regions but differ significantly at the Central region (Fig. 7 bottom panel). The patterns in both zooplankton and detritus concentrations closely followed the phytoplankton concentration patterns (Fig. 8 and 9).

In experiment E3, phytoplankton growth is temperature independent and has a low $P_{\max }\left(0.7 \mathrm{~d}^{-1}\right)$ value, which is the average from U.S. JGOFS data (Caron and Dennett, 1999). The E3 simulations produce unrealistically high nutrient concentrations in the mixed layer everywhere in the domain all year-round (Fig. 6), although the shape of the time evolution is similar to that of E1. The phytoplankton concentrations in this experiment are much reduced although there is still a weak SWM bloom in the Somali and Omani regions (Fig. 7). Off the coast in the Central region, the results of E2 and E3 are very similar but differ significantly from E1. Zooplankton and detritus concentrations in E3 also closely follow patterns produced by the phytoplankton compartment 

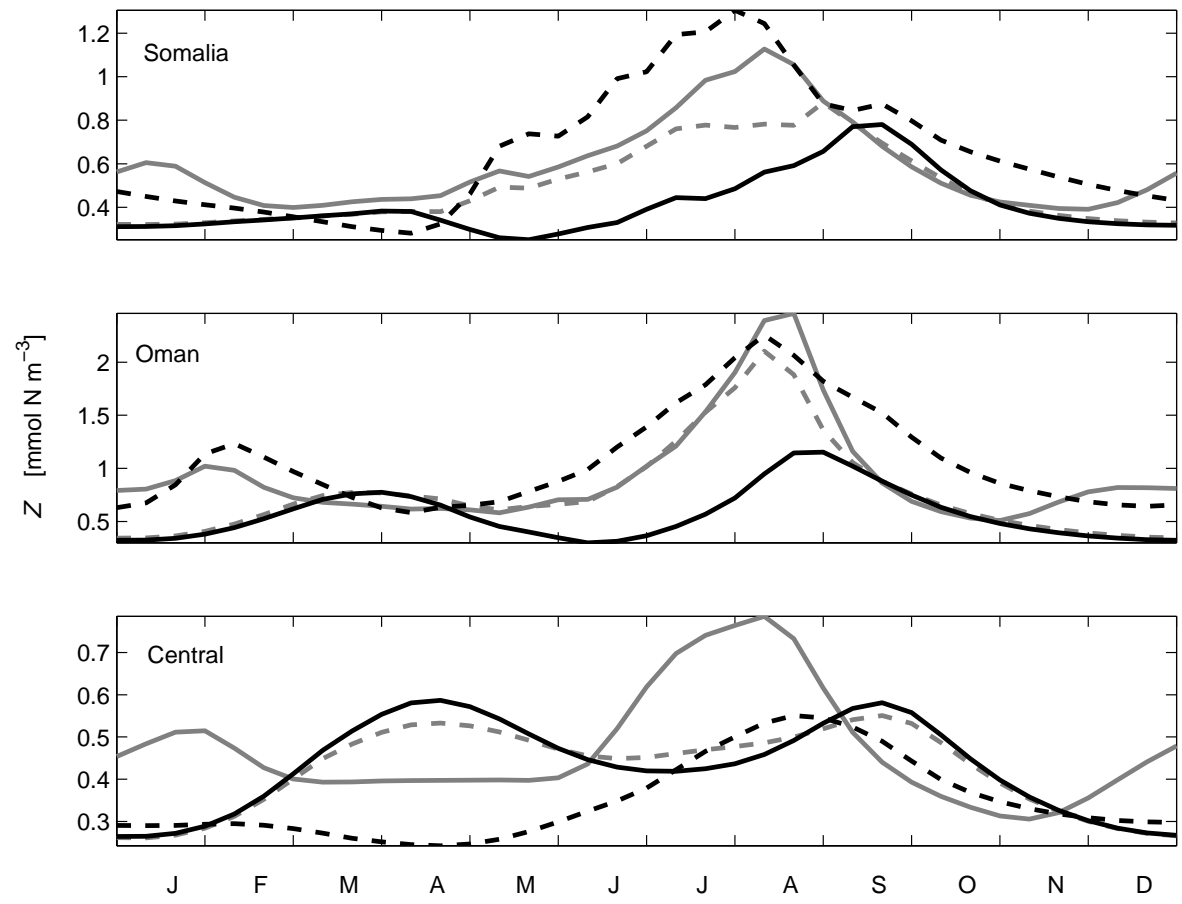

Fig. 8. Annual cycle of the zooplankton concentration in the mixed layer in three regions indicated in Fig. 1 as predicted by experiments E1 (solid light), E2 (dashed light), E3 (solid dark) and E4 (dashed dark). Description of the different experiments is given in Table 2. Note scale changes among panels.

(Figs. 8 and 9).

In experiment E4, phytoplankton growth is again temperature independent and uses the highest $\gamma_{\max }$ and $P_{\max }\left(1 \mathrm{~d}^{-1}\right.$ and $2 \mathrm{~d}^{-1}$, respectively) values, which are the most common in the literature (Lima et al., 2002). Nutrient concentrations produced by experiment E4 are consistently the lowest in Somali waters and the central basin (Fig. 6). In the Omani region, the nutrient concentration produced by experiment E4 presents a short-lived NEM peak and a SWM peak similar to E1 and E2 experiments. Phytoplankton blooms produced in E4 within coastal Somali and Omani waters start slightly earlier than those in E1, and last longer periods (Fig. 7). There is also an NEM bloom of phytoplankton in coastal Omani waters in experiment E4. The SWM peak concentrations in zooplankton and detritus are highest in experiment E4 compared to the other simulations (Fig. 8 and 9). The elevated concentrations in zooplankton and detritus lasted over an extended period in both Somali and Omani waters.

Overall, the nutrient concentration stands out as the most sensitive variable to variations in the ecosystem model parameters according to the experiments presented here. The Central region is where the differences between the results of different experiments are the largest in all of the ecosystem variables. The phytoplankton bloom off the Omani coast after the NEM is found quite 

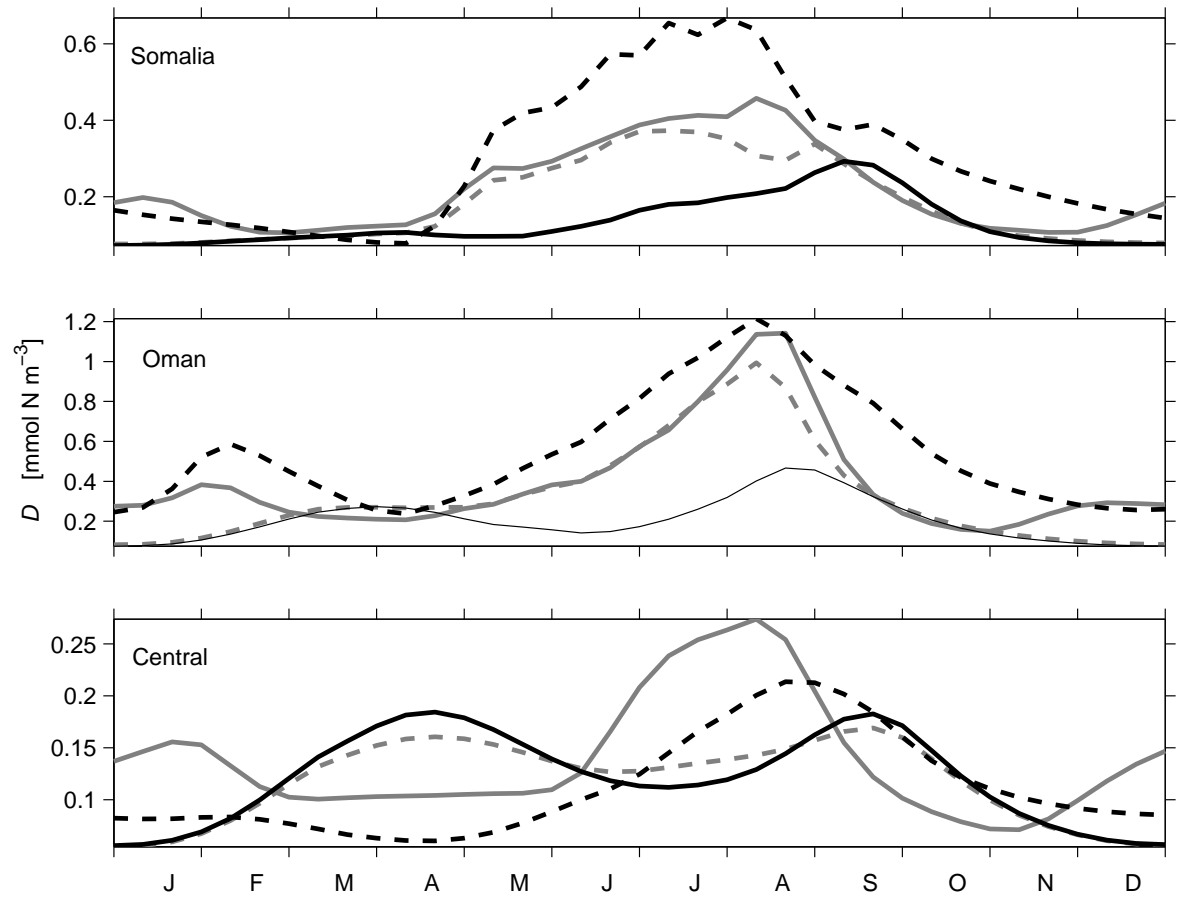

Fig. 9. Annual cycle of the detritus concentration in the mixed layer in three regions indicated in Fig. 1 as predicted by experiments E1 (solid light), E2 (dashed light), E3 (solid dark) and E4 (dashed dark). Description of the different experiments is given in Table 2. Note scale changes among panels.

sensitive to variations of parameter.

\subsubsection{Detritus sinking rate}

Figures 10 and 11 show the concentrations of nutrients and phytoplankton for three detritus sinking rates as predicted by the baseline experiment E1 and experiments E5 and E6 (cf. Table 2). In general, the NPZD variables (zooplankton and detritus not shown) have the same patterns but with higher concentrations in the experiment with no detritus sinking (E6) and decreasing concentrations as the sinking rate increases. This is not the case in the Omani region, where as the detritus sinking rate increases the nutrients in the mixed layer and intermediate depth layers (not shown) are higher every year. Kawamiya and Oschlies (2003) reported a similar trend in their model. As a consequence of nutrient concentration behavior, phytoplankton concentrations in the SWM bloom increase as detritus sinking rates increase in the Omani region. Notice that even though the nutrient concentration does not attain an equilibrium in this region, the rest of the variables are able to reach an equilibrium. This deserves further discussion and is given next.

The global ocean and individual basins around the world reprocess nutrients through the processes that are adequately represented in the current model. In addition there is denitrification in coastal sediments and at mid-depths in 

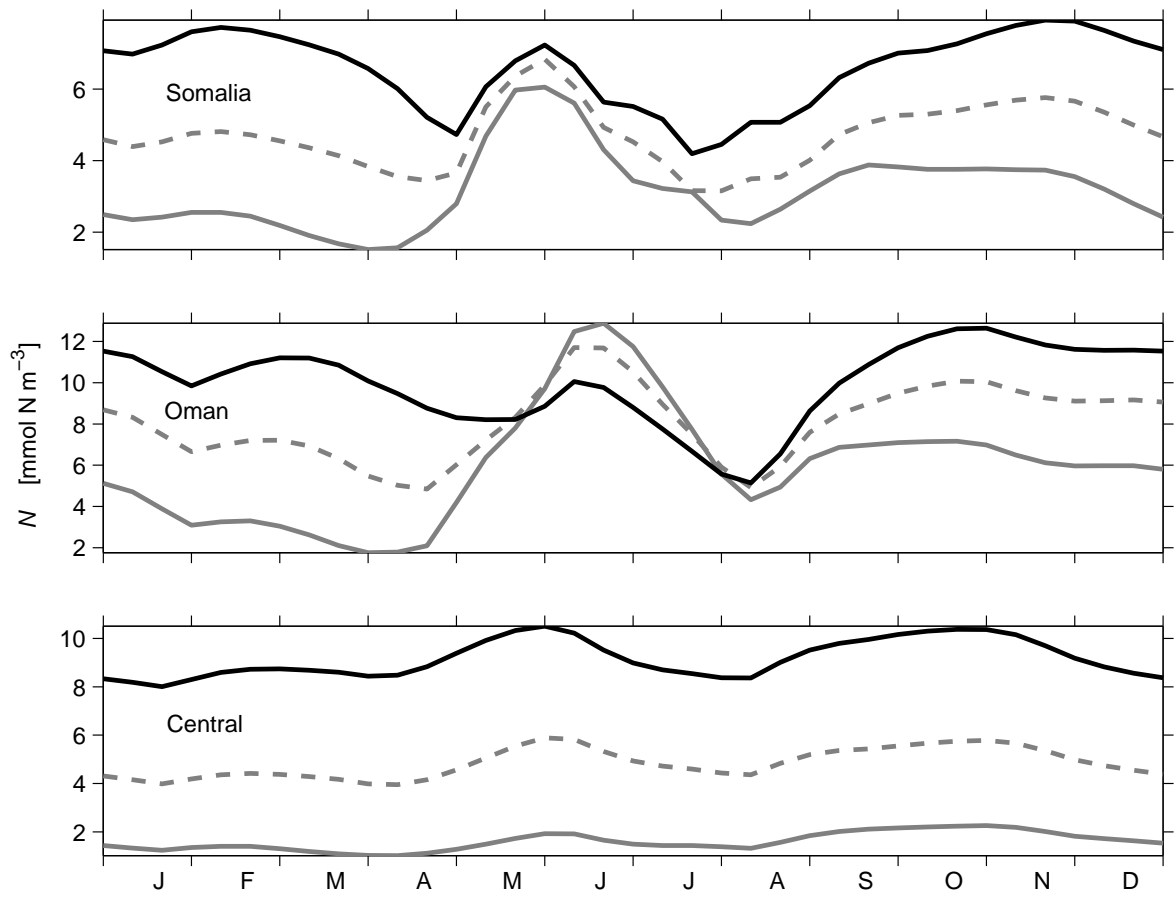

Fig. 10. Annual cycle of nutrient concentration in the mixed layer in three regions indicated in Fig. 1 as predicted by experiments E1 (solid light), E5 (dashed light), and E6 (solid dark). Description of the different experiments is given in Table 2. Note scale change among panels.

the Arabian Sea (Olson et al., 1993; Naqvi et al., 1992), and nitrogen fixation in the surface layers (Capone and Carpenter, 1982). Since neither of these processes are included in the present model, the model only includes refraction of the nitrogen in the inorganic, $N$, pool by upwelling and vertical losses to the deeper fluid feeding the upwelling via the sinking and remineralization of particles. Ignoring the existence of source/sink terms tied to $N$-fixation and denitrification, the model provides an estimate of the refraction process inherent in the upwelling process and the subsequent flux of nitrogen back into the upwelled fluid by sinking. This produces a loop in the nitrogen cycle closed within the Arabian Sea Basin. Newly upwelled fluid along the Omani coast, where advection is slower, have a net accumulation of nutrients. This is due to the introduction of nitrogen to the thermocline waters by remineralization of sinking particles created from previous upwelling of nutrients. In the global ocean this is the process that creates the global gradients in nutrients in the deep ocean.

Accounting for the missing sources and sinks of nutrients in a basin would require even more sophisticated ecosystem model equations, which would of course add even more uncertainties to the modelling efforts. 

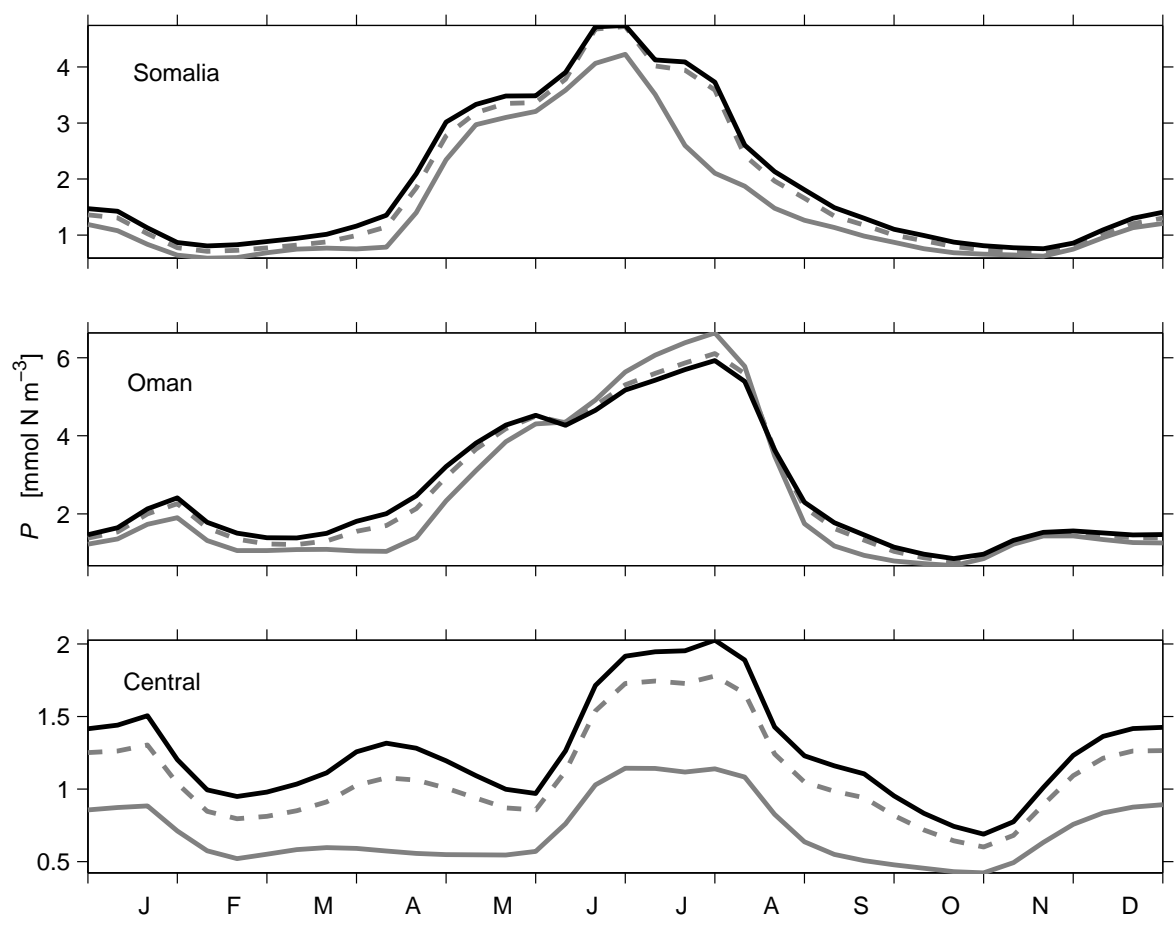

Fig. 11. Annual cycle of phytoplankton concentration in the mixed layer in three regions indicated in Fig. 1 as predicted by experiments E1 (solid light), E5 (dashed light), and E6 (solid dark). Description of the different experiments is given in Table 2. Note scale change among panels.

\subsection{Comparison with data}

\subsubsection{U.S. JGOFS data}

In this section, the model results from experiment E1 are compared to in situ observations during an annual cycle at two specific U.S. JGOFS stations off the Omani coast. These stations chosen here are representative of coastal (S2) and offshore (S15) biological conditions. The U.S. JGOFS cruises considered in this paper cover each of the 1995 seasons: TN043 (middle NEM), TN045 (spring intermonsoon), TN049 (middle SWM), TN050 (late SWM), and TN054 (early NEM). Wind data from the central air-sea interaction mooring at $15^{\circ} 30^{\prime} \mathrm{N}$ $61^{\circ} 30^{\prime} \mathrm{E}(1994-1995)$ show that the SWM of 1995 is almost as intense as the climatological average, but in other months, like in May, the wind speed is $50 \%$ higher than the climatological average (Smith et al., 1998). It is important to recall here that the model is forced by monthly-averaged values, so the comparisons are only expected to be qualitative.

Model nutrient concentrations are compared with in situ $\mathrm{NO}_{3}+\mathrm{NO}_{2}+\mathrm{NH}_{3}$ from the inshore station (S2) and the offshore station (S15) (Fig. 12 upper and bottom panels respectively). At station $\mathrm{S} 2$, the in situ data show clear nutriclines between 50 and $100 \mathrm{~m}$ during the NEM and the intermonsoon periods (first, second and last profiles in the upper panel), but no clear nutricline 

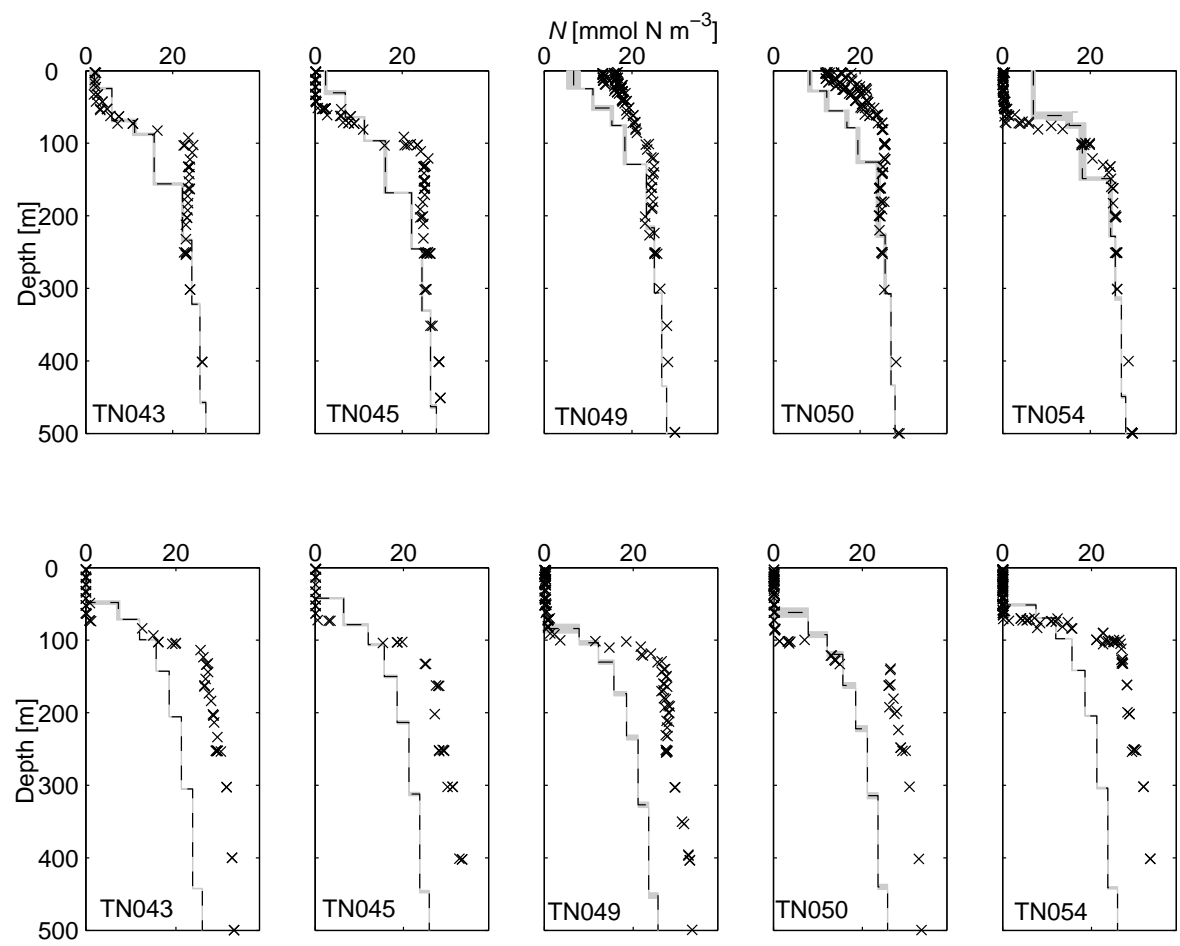

Fig. 12. Comparison between modeled (experiment E1) and observed (crosses) vertical distribution of nutrients at station S2 (upper panels) and S15 (lower panels) for the 1995 U.S. JGOFS cruises: TN043 (middle NEM), TN045 (spring intermonsoon), TN049 (middle SWM), TN050 (late SWM), and TN054 (early NEM). The shaded bands represent a one standard deviation variability in the modeled nutrient concentration and layer depth within a $20 \mathrm{~d}$ period.

during the SWM cruises (third and fourth profiles in the upper panel). The modeled nutricline, in general, is less abrupt but does occur at similar depths as in the observations. During the SWM the mixed layer nutrient concentrations in the model underestimate the in situ data. On the other hand, at the beginning of the NEM, the model overestimates the observed nutrient concentrations in the mixed layer. In the deeper layers (roughly below $200 \mathrm{~m}$ ) there is very good agreement between observations and model.

Regarding the model nutricline at station S15, the range of model concentrations between the surface and deep layers is not as extensive as in the data. Nutricline depths from data range between 70 and $120 \mathrm{~m}$, deeper than at S2, and model nutricline depths are usually somewhat shallower. The model mixed layer concentrations are in agreement with the observations but in the deeper layers (below $100 \mathrm{~m}$ ) the model underestimates nutrient content significantly.

In Fig. 13 the model phytoplankton concentration is compared to the in situ data at station S2 and S15 for the different U.S. JGOFS cruises. For comparative purposes, model chlorophyll $a$ values are calculated using 1:50 C:Chl ratio, and a C:N ratio 106:16 (the Redfield ratio). The model overestimates 

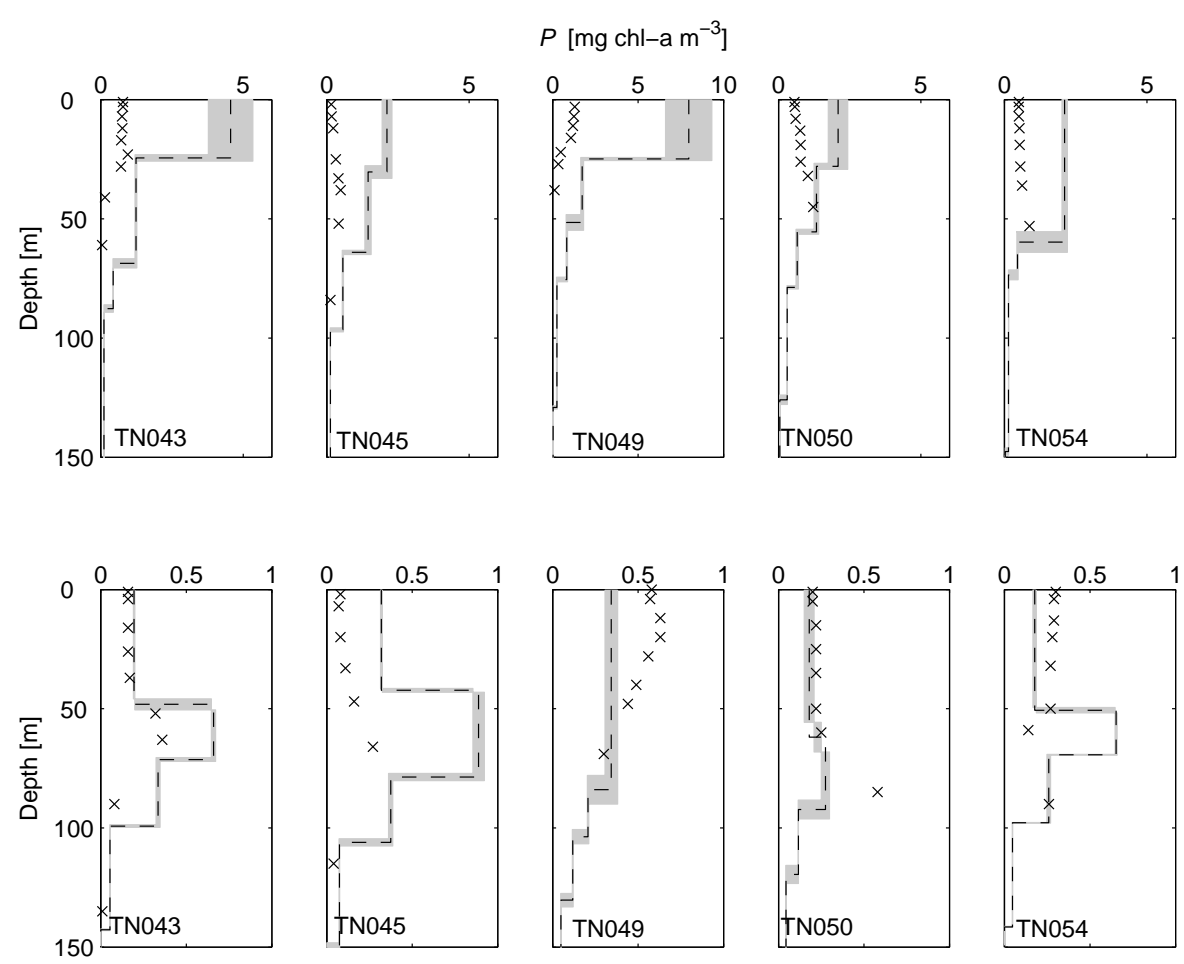

Fig. 13. Comparison between modeled (experiment E1) and observed (crosses) vertical distribution of phytoplankton at station S2 (upper panels) and S15 (lower panels) for the 1995 U.S. JGOFS cruises: TN043 (middle NEM), TN045 (spring intermonsoon), TN049 (middle SWM), TN050 (late SWM), and TN054 (early NEM). The shaded bands represent a one standard deviation variability in the modeled phytoplankton concentration and layer depth within a 20 day period. Note scale changes among panels.

the chlorophyll a concentrations with respect to in situ data at station S2. At station S15, the maximum concentration of chlorophyll $a$ is observed in late July. A clear DCM is observed from September to March. Notice that at this location both the annual cycle and phytoplankton concentration are in good agreement with the observations.

Fig. 14 shows the vertical distribution of zooplankton at stations along the south transect of the U.S. JGOFS study during August (cruise TN050, upper panel) and December (cruise TN054, lower panel). Observations indicate that zooplankton concentration decreases from the coast (S2) to the interior ocean (S15) during the August cruise. Model zooplankton captures this trend fairly well and within two standard deviations both in the mixed layer and at depth (Fig. 14, upper panel). Zooplankton concentrations are higher during August (the end of the SWM) than during December. During December zooplankton concentrations generally decrease away from the shore with an exception at S7, where maximum concentration is observed (Fig. 14, lower panel). During December model zooplankton concentrations, in general, underestimate surface daytime net-tow data. 

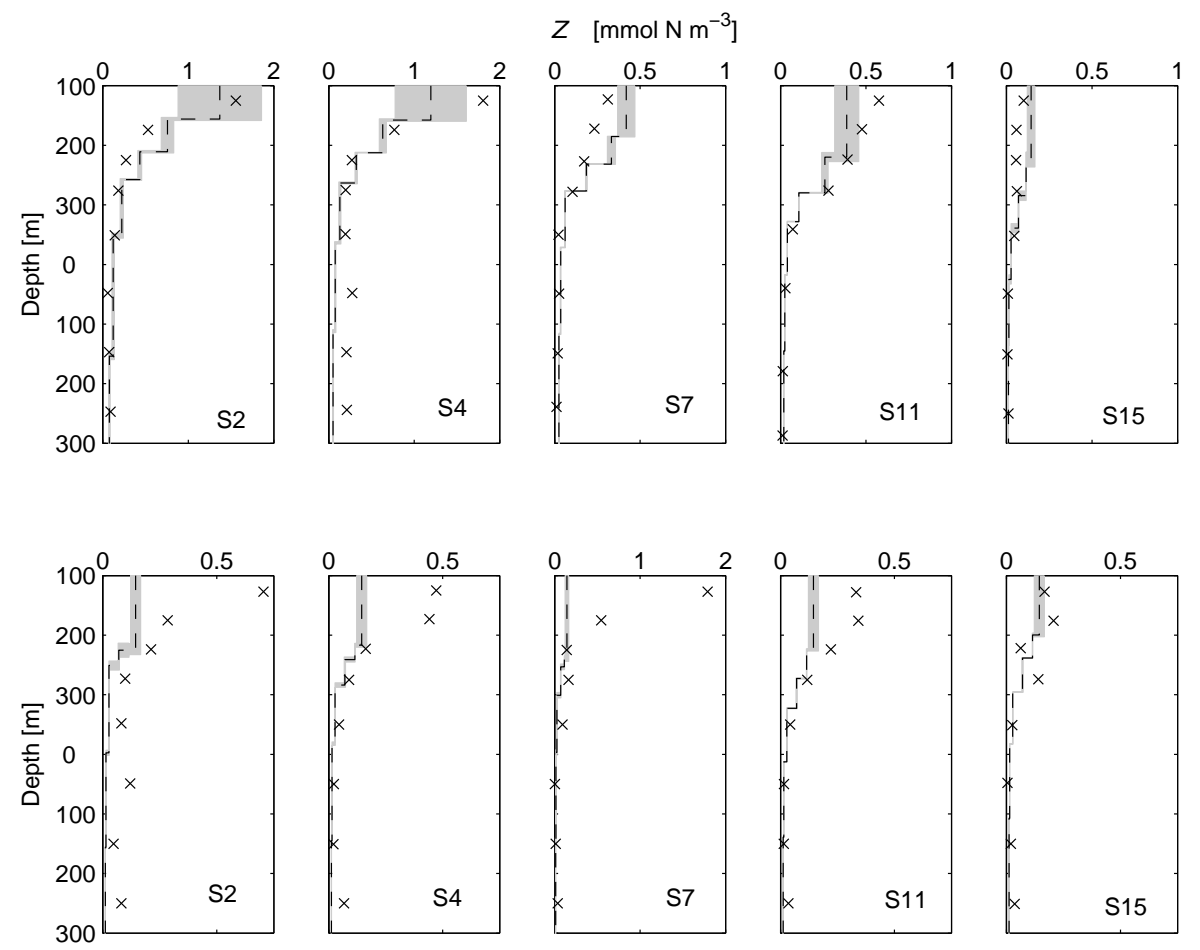

Fig. 14. Comparison between modeled (experiment E1) and observed (crosses) vertical distribution of zooplankton along the south transect of U.S. JGOFS (cf. Fig. 1) for August (cruise TN050, upper panels) and December (cruise TN054, lower panels). The shaded bands represent a one standard deviation variability in the modeled zooplankton concentration and layer depth within a $20 \mathrm{~d}$ period. Note scale changes among panels.

\subsubsection{Sea-viewing Wide Field-of-view Sensor (SeaWiFS) data}

The concentration of phytoplankton in the global ocean is derived from satellite observation and quantification of subtle changes in the ocean color. An algorithm based on the blue and green channels derives the concentration of the photosynthetic pigment chlorophyll $a$ in ocean phytoplankton. The SeaWiFS measurements used here are for the period 2000-2002 over the Arabian Sea.

During the SWM, all the experiments predict phytoplankton distributions that are in general agreement with the chlorophyll $a$ distributions inferred from SeaWiFS. However, the model overestimates the SeaWiFS-derived chlorophyll $a$ concentrations, and just the northern edge of the Great Whirl is clearly observed in SeaWiFS data. During the NEM, the SeaWiFS data show a phytoplankton bloom in the northern Arabian Sea with moderate concentrations extending offshore. This is largely captured by the all of the experiments described here.

Fig. 15 shows weekly averaged SeaWiFS data from 2000 to 2002. The error 

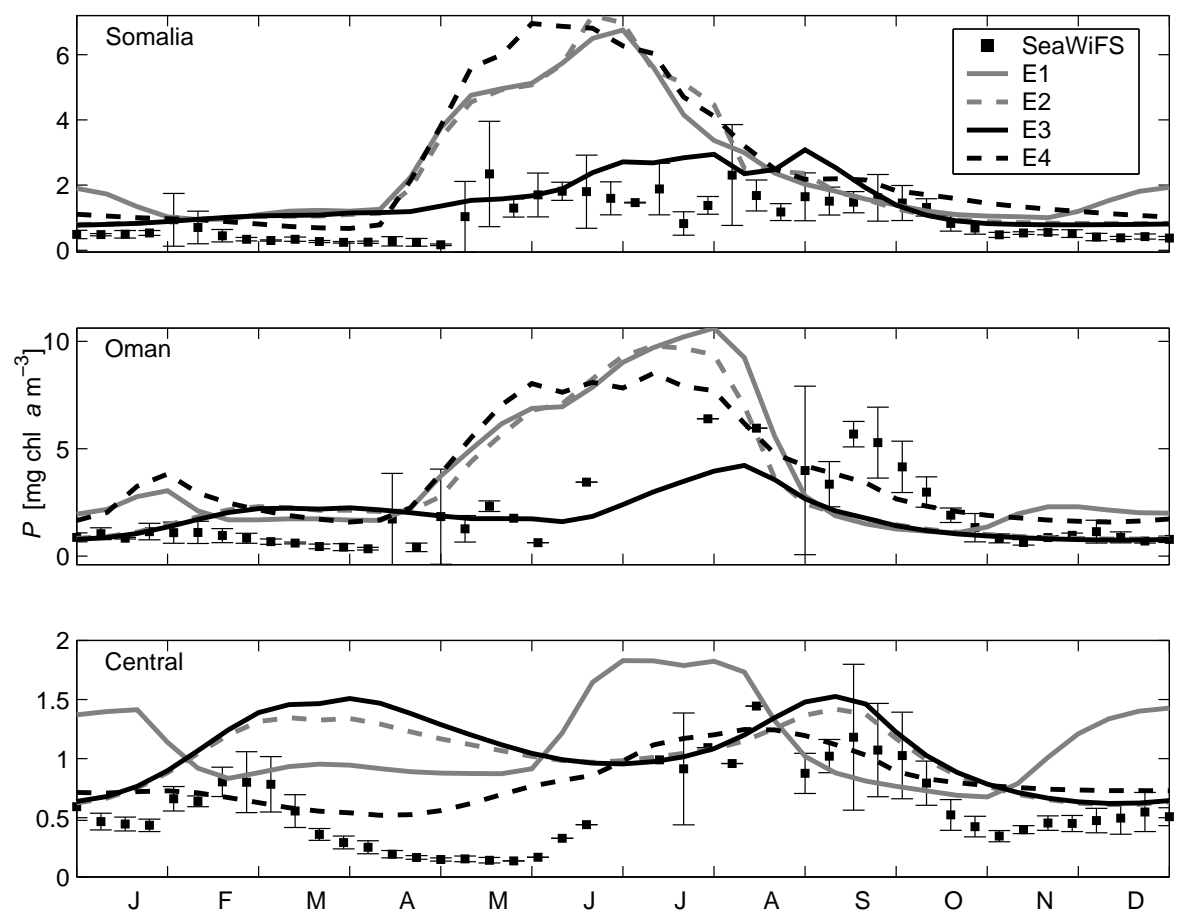

Fig. 15. Horizontal average of phytoplankton concentration within the Somali, Omani, and Central regions as predicted by experiments E1, E2, E3, and E4, and as inferred form SeaWiFS data, weakly averaged during the 2000-2002 period (errorbars are of one standard deviation). Description of the different experiments is given in Table 2. Note scale changes among panels.

bars on SeaWiFS chlorophyll $a$ represents the standard deviation within the three years of data. The modeled chlorophyll $a$ for experiments E1, E2, E3, and E4 are also displayed. The comparison shows a general correspondence between the averaged SeaWiFS data and model chlorophyll $a$.

In the Somali region (Fig. 15, upper panel) a summer bloom is captured in both the data and the model (experiments E1, E2 and E4), but the chlorophyll $a$ concentration obtained from the model is, in general, higher than in the SeaWiFS data. Notice also that the bloom lasts longer in the SeaWiFS data and is not as sharp as compared to the model results. However, experiment E3 predicts much a less intense bloom and is in closer agreement to SeaWiFS suggesting that a reduced maximum phytoplankton growth rate is more appropriate parameter choice for the Somali region (cf. Table 2). From in situ data we know that the average concentration for the region during the SWM is about $3 \mathrm{mg}$ chl $a \mathrm{~m}^{-3}$, with concentrations as high as $15 \mathrm{mg} \operatorname{chl~} a \mathrm{~m}^{-3}$ (Veldhuis et al., 1997; Baars et al., 1994).There is evidence of another bloom in winter in the SeaWiFS data but it is not present in any of the experiments. This bloom is within the standard deviation, implying that it is part of the interannual variability.

The Omani region (Fig. 15, central panel) presents a marked seasonal signal, 
with a prominent SWM bloom. The intensity of this bloom is captured by model experiments E1, E2 and E4. Experiment E3 predicts a much less intense and shorter bloom. The late winter bloom, which is present in the model for experiments E1 and E4, is less intense in the SeaWiFS data. This bloom has also been documented through in situ data (Gundersen et al., 1998).

The Central region (Fig. 15, bottom panel) exhibits oligotrophic conditions in both SeaWiFS data and model results. SeaWiFS data present two small peaks in the chlorophyll $a$ concentration during the SWM and NEM. There is no agreement among the results of model experimenters in this region as was discussed in Section 4.2. Experiments E2 and E3 have better agreement but even then the Spring bloom lasts longer and the Fall bloom starts latter compared to the observations.

The SeaWiFS data reveal significant interannual variability in surface chlorophyll a concentrations (Wiggert et al., 2000). Future biophysical modelling efforts should include the interannual variability of the forcing agents in order to reproduce this aspect of the plankton dynamics.

\subsection{Comparison with other models}

Most of the modelling efforts to date as well as the present one, predict a phytoplankton bloom in the Somali and Omani regions during the SWM season. Notwithstanding, differences among the various model solutions are found in the duration and intensity of this bloom. For instance, Ryabchenko et al. (1998) predict a short-lasting bloom. Most experiments described in this paper predict, in general, elevated phytoplankton concentrations compared to earlier model predictions. The few in situ observations predict less intense blooms and although the more abundant satellite data indicate much higher concentrations, these are not as high as in the present model. With respect to zooplankton concentration during the SWM bloom, McCreary et al. (1996) predict lower concentrations (less than $0.6 \mathrm{mmol} \mathrm{N} \mathrm{m}{ }^{-3}$ ) compared to the rest of the models. Ryabchenko et al. (1998) attributed this behavior to the use of self predation in their NPZD equations. However, the NPZD set considered here includes a similar zooplankton self-predation term, and the predicted zooplankton concentrations $\left(1-2 \mathrm{mmol} \mathrm{N} \mathrm{m}^{-3}\right)$, which are much higher than in McCreary et al. (1996), appear to be in better agreement with the in situ observations.

The largest differences among the previous models are found in the Central region. For instance, McCreary et al. (1996) and Ryabchenko et al. (1998) predict unrealistically high nutrient concentrations there. Also, in this region McCreary et al. (1996) and Ryabchenko et al. (1998) predict two phytoplankton blooms for which there is evidence in SeaWiFS (cf. Section 4.3.2) while Kawamiya and Oschlies (2003) do not. McCreary et al. (1996) and Ryabchenko et al. (1998) explain the phytoplankton blooms as a result of an abrupt change 
in the mixed layer depth and the available nutrient concentrations within the mixed layer. However, the observed nutrient concentrations are not higher than $2 \mathrm{mmol} \mathrm{N} \mathrm{m}^{-3}$ during the SWM and the observed change in the mixed layer depth is not as abrupt as in their models (Kawamiya and Oschlies, 2003). The change in the mixed layer depth predicted here is fairly realistic (it decreases from $60 \mathrm{~m}$ in July to $40 \mathrm{~m}$ in September; and from $70 \mathrm{~m}$ at the end of December to $40 \mathrm{~m}$ in March). The phytoplankton blooms occur in all of the experiments here, though not simultaneously, despite the fact that the amount of nutrients available in the mixed layer changes considerably from one experiment to the other. In experiments E2 and E3 the fall and spring blooms are clearly the result of detrainment according to McCreary et al.'s (1996) classification. In these two experiments the nutrients are not as high as in McCreary et al. (1996) and Ryabchenko et al. (1998) (between 3 and 5 mmol $\mathrm{N} \mathrm{m}^{-3}$ ) and occur when the mixed layer depth decreases. However, in experiments E1 and E4 the blooms occur before the mixed layer shallows and there is no marked peak in the nutrient concentration before the blooms take place.

As compared to in situ and satellite data, the results from the present model seem to be at least as good as those from earlier models of the Arabian Sea biological activity. Our model does not appear to perform much better or worse than the previous models. Furthermore, neither the results from this multi-isopycnic-layer modelling effort nor those from the previous fixed-level (Kawamiya and Oschlies, 2003) modelling efforts amounted to a considerable improvement with respect to the (conceptually much simpler but numerically less expensive) two-inhomogeneous-layer reduced-gravity model of McCreary et al. (1996). The results from the present sensitivity experiments suggest that the unrealistic nonoligotrophic conditions predicted by McCreary et al. (1996) in the Central region could be substantially improved by appropriately modifying the ecosystem model parameters. In fact McCreary et al.'s (2001) and Hood et al. (2003) who considered only two more active layers than McCreary et al. (1996), were able to fix McCreary et al.'s (1996) unrealistic nonoligotrophic conditions mainly by reducing the light saturation constant and increasing the detritus sinking rate.

We close by remarking that even though more work should of course be devoted to improve the biophysical modelling in the Arabian Sea, this task could certainly be facilitated by considering simple (few-layer surface-confined) underlying hydrodynamics. However, if the focus is on the biological aspects of a particular deep ocean isopycnal, e.g. as in Idrisi et al. (2003) who modeled the motion of dormant copepods as Lagrangian particles, a configuration like the one considered in the present NPZD-MICOM coupled model is needed. 


\section{Conclusions}

A Nutrients-Phytoplankton-Zooplankton-Detritus (NPZD) biological model has been coupled to the Miami Isopycnic-Coordinate Ocean Model (MICOM) to study plankton dynamics in the Arabian Sea. Several numerical experiments were carried out to analyze the sensitivity of the NPZD-MICOM coupled model to variations in the ecosystem model parameters.

Over the course of a year, the NPZD-MICOM coupled model reproduces the seasonal patterns observed in the region. Specifically, the model produces a pronounced response in the biology off Oman compared to Somalia, both in terms of concentration and horizontal coverage of blooms generated during the South West Monsoon. The phytoplankton blooms off Somalia are a direct consequence of upwelled and advected waters around the edges of the Great Whirl. The model is also able to reproduce blooms off the northeast coast of Oman during the North East Monsoon through convective mixing. The offshore and intermonsoon oligotrophic conditions are also captured by the model as well as the offshore deep chlorophyll maximum. The model results are in agreement with (the scarce) in situ and satellite data in terms of reproducing temporal and spatial variability in nutrients, phytoplankton and zooplankton concentrations at least qualitatively.

As isopycnic models are known to easily and accurately represent upwelling dynamics, ecosystem modelling based on these models was expected to be substantially improved and enriched. This expectation, however, was tempered significantly here. The present results have the same virtues and deficiencies as those of earlier biophysical modelling efforts which considered quite different hydrodynamical models (few-inhomogeneous-layer reduced-gravity, multi-homogeneous-layer, or fixed-level). The differences between the results and those from the previous works in the area are in the same range as the differences among the results from the various experiments presented here, which are all based on the same hydrodynamical model. This suggests that a small uncertainty in the knowledge of the ecosystem model parameters can produce larger effects on the modelling of biophysical interactions than those associated to the differences between the type of hydrodynamical model to which the biology is coupled. However, because the NPZD sets employed in the earlier and the present modelling efforts are not exactly identical, further research is needed to make stronger assessments of the relative importance of biological model parameters uncertainty against hydrodynamical model type. The flexibility of the Hybrid Coordinate Model (Bleck, 2002) to the choice of vertical coordinate (isopycnic, fixed-level, or hybrid isopycnic-fixed-level)

is currently being exploited to thoroughly analyze the response of the same ecosystem model to variations in the vertical coordinate representation.

That the present multi-isopycnic-layer model performed at least as well as 
earlier fewer-layer, reduced-gravity models of the area is not surprising since NPZD dynamics develop mainly in the uppermost layers of the ocean. However, there are still biological processes, such as denitrification which affect the vertical distribution of nutrient concentrations, that are not included neither in the previous works in the area nor in the present model. This might mask any potential advantages of the present MICOM-NPZD coupled model, especially at mid- and greater depths in the ocean. Finally, multi-isopycnic modelling is largely convenient when the focus is on the study of how the hydrodynamics affects the distribution of species that spend a good part of their life in deeper ocean layers, such as copepods in their dormant stages (Idrisi et al., 2003).

\section{Acknowledgments}

We thank S. L. Smith, D. B. Olson, and F. J. Beron-Vera for their valuable help and assistance. We also thank P. Lane, M. Iskandarani, E. Chassignet, and A. Mariano for useful discussions. Ivan Lima provided the original NPZD model. The configuration of MICOM for the Arabian Sea is due to E. Esenkov. Peter Lane processed the data from the U.S. JGOFS cruises, and V. Banzon and A. Kumar the SeaWiFS data. This research was supported by the National Science Foundation under grant OCE-9911494.

\section{References}

Baars, M. A., Bakker, K. M. J., de Bruin, T. F., van Couwelaar, M., Hiehle, M. A., Kraay, G. W., Oosterhuis, S. S., Schalk, P. H., Sprong, I., Vedhuis, M. J. W., Wiebinga, C. J. and Witte, J. J. (1994). Overview of the scientific background and general results., in M. A. Baars (ed.), Monsoon and Pelagic Systems, National Museum of natural history, Leiden, chapter Cruise reports Netherlands Indian Ocean Programme Vol. 1, pp. 13-34.

Bleck, R. (2002). An oceanic general circulation model framed in hybrid isopycnicCartesian coordinates, Ocean Modelling 37: 55-88.

Bleck, R., Rooth, C., Hu, D. and Smith, L. (1992). Salinity-driven thermocline transients in a wind- and thermohaline-forced isopycnic coordinate model of the North Atlantic, J. Phys. Oceanogr. 22: 1486-1505.

Bleck, R. and Sun, S. (1996). Open boundary conditions for MICOM, Office notes pp. $1-3$.

Capone, D. G. and Carpenter, E. J. (1982). Nitrogen fixation in the marine enviroment, Science 217: 1140-1142.

Caron, D. A. and Dennett, M. R. (1999). Phytoplankton growth and mortality during the 1995 northeast monsoon and spring intermonsoon in the arabian sea, Deep-Sea Res. II 46: 1665-1690.

Chassignet, E. P., Smith, L. T., Bleck, R. and Bryan, F. O. (1996). A model comparison: Numerical simulations of the north and equatorial atlantic oceanic circulation in depth and isopycnic coordinates, J. Phys. Oceanogr. 26: 18491867.

Eppley, R. W. (1972). Temperature and phytoplankton growth in the sea, Fishery Bulletin 70: 1063-1085. 
Esenkov, O. E. (2000). A Numerical Study of the Dynamics of the Somali Current Sytem, $\mathrm{PhD}$ thesis, University of Miami.

Esenkov, O. and Olson, D. B. (2002). A numerical study of the Somali coastal undercurrent, Deep-Sea Res. II pp. 1,253-1,277.

Esenkov, O., Olson, D. B. and Bleck, R. (2003). A study of the circulation and salinity budget of the arabian sea with an isopycnic coordinate ocean model, Deep-Sea Res. II 50: 2,091-2,110.

Flagg, C. N. and Kim, H. S. (1998). Upper ocean currents in the northern Arabian Sea from shipboard ADCP measurements collected during the 1994-1996 U.S. JGOFS and ONR programs, Deep-Sea Res. II 45: 1917-1959.

Gardner, W. D., Gundersen, J. S., Richardson, M. J. and Walsh, I. D. (1999). The role of seasonal and diel change in mixed-layer depth on carbon and chlorophyll distributions in the Arabian Sea, Deep-Sea Res. II 46: 1833-1858.

Garrison, D. L., Gowing, M. M., Hughes, M. P., Campbell, L., Caron, D. A., Dennett, M. R., Shalapynok, A., Olson, R. J., Landry, M. R., Brown, S. L., Liu, H., Azam, F., Steward, G. F., Ducklow, H. W. and Smith, D. C. (2000). Microbial food web structure in the arabian sea: A US JGOFS study, Deep-Sea Res. II 47: 1387-1422.

Griffies, S. M., Pacanowski, R. C. and Hallaberg, R. W. (2000). Spurious diapycnal mixing associated with advection in a $z$-coordinate ocean model, J. Phys. Oceanogr. 128: 538-564.

Gundersen, J. S., Gardner, W. D., Richardson, M. J. and Walsh, I. D. (1998). Effects of monsoons on the seasonal and spatial distributions of POC and chlorophyll in the Arabian Sea, Deep-Sea Res. II 45: 2103-2132.

Hood, R. R., Kohler, K. E., Jr., J. P. M. and Smith, S. L. (2003). A 4-dimensional validation of a coupled physical-biological model of the Arabian Sea, Deep-Sea Res., in press.

Idrisi, N., Olascoaga, M. J., Garraffo, Z., Olson, D. B. and Smith, S. L. (2003). Mechanisms for emergence from diapause of Calanoides carinatus in the Somali Current, Limnology and Oceanography, in press.

Kawamiya, M. (2001). Mechanism of offshore nutrient supply in the western arabian sea, J. Mar. Res. 59: 675-696.

Kawamiya, M. and Oschlies, A. (2003). An eddy-permitting, coupled ecosystemcirculation model of the arabian sea, J. Mar. Sys. 38: 221-257.

Keen, T. R., Kindle, J. C. and Young, D. K. (1997). The interaction of southwest monsoon upwelling, advection and primary production in the northwest Arabian Sea, J. Mar. Sys. 13: 61-82.

Kim, H.-S., Flagg, C. N. and Howden, S. D. (2001). Northern arabian sea variability from TOPEX/Poseidon altimetry data: An extension of the US JGOFS/ONR shipboard ADCP study, Deep-Sea Res. II 48: 1069-1096.

Krey, J. (1973). Primary Production in the Indian Ocean I, Springer, Berlin.

Latasa, M. and Bidigare, R. R. (1998). A comparison of phytoplankton populations of the Arabian Sea during the Spring Intermonsoon and Southwest Monsoon of 1995 as described by HPLC- analysed pigments, Deep-Sea Res. II 45: 21332170.

Levitus, S. and Boyer, T. P. (1994). World Ocean Atlas, Technical Report 3, NOAA.

Lima, I. D., Olson, D. B. and Doney, S. (2002). Intrinsic dynamics and stability properties of size-structured pelagic ecosystem models, J. Plankton Res. 24: $533-556$. 
McCreary, J. P., Kohler, K. E., Hood, R. R. and Olson, D. B. (1996). A fourcomponent ecosystem model of biological activity in the Arabian Sea, Prog. Oceanog. 37: 193-240.

McCreary, J. P., Kohler, K. E., Hood, R. R., Smith, S., Fischer, A. S. and Weller, R. A. (2001). Influences of diurnal and intraseasonal forcing on mixed-layer and biological variability in the central arabian sea, J. Geophys. Res. 106: 71397155 .

Naqvi, S. W. A., Noronha, R. J., Shailaja, M. S., Somasundar, K. and Grupta, R. S. (1992). Some Aspects of the Nitrogen Cycling in the Arabian Sea., pp. 285-311.

Olson, D. B., Hitchcock, G. L., Fine, R. A. and Warren, B. A. (1993). Maintenance of the low-oxygen layer in the central arabian sea, Deep-Sea Res. II 40: 673685.

Roman, M., Smith, S., Wisshner, K., Zhang, X. and Gowing, M. (2000). Mesozooplankton production and grazing in the arabian sea, Deep-Sea Res. II 47: 1423-1450.

Ryabchenko, V. A., Gorchakov, V. A. and Fasham, M. J. R. (1998). Seasonal dynamics and biological productivity in the Arabian sea euphotic zone as simulated by a three-dimensional ecosystem model, Global Biogeochemical Cycles 12: 501-530.

Smith, S., Roman, M., Prusova, I., Wishner, K., Gowing, M., Codispoti, L. A. and Flagg, C. (1998). Seasonal response of zooplankton to monsooonal reversals in the Arabian Sea, Deep-Sea Res. II 45: 2369-2404.

Spitz, Y. H., Newberger, P. A. and Allen, J. S. (2003). Ecosystem Response to Upwelling Off the Oregon Coast: Behavior of Three Nitrogen-Based Models, $J$. Geophys. Res. 108: C3.

Thornton, K. W. and Lessem, A. S. (1978). A temperature algorithm for modifying biological rates, Trans. Am. Fish. Soc. 107: 284-287.

van Couwelaar, M. (1997). Zooplankton and micronekton biomass off somalia and in the southern red sea during the SW monsoon of 1992 and the NE monsoon of 1993, Deep-Sea Res. II 44: 1,213-1,234.

Veldhuis, M. J. W., Kraay, G. W., van Bleijswijk, J. D. L. and Baars, M. A. (1997). Seasonal and spatial variability in phytoplankton biomass, productivity and growth in the nothwestern indian ocean: The southwest and northeast monsoon, 1992-1993, Deep-Sea Res. I 44: 425-449.

Wiggert, J. D., Jones, B. H., Dickey, T. D., Brink, K. H., Weller, R. A., Marra, J. and Codispoti, L. A. (2000). The northeast monsoon's impact on mixing, phytoplankton biomass and nutrient cycling in the arabian sea, Deep-Sea Res. II 47: 1353-1385. 